\title{
Handling tRNA introns, archaeal way and eukaryotic way
}

\section{Tohru Yoshihisa *}

Graduate School of Life Science, University of Hyogo, Ako-gun, Hyogo, Japan

\section{Edited by:}

Akio Kanai, Keio University, Japan

Reviewed by:

Akiko Soma, Chiba University, Japan Javier Augusto Martinez, Institute of Molecular Biotechnology, Austria

\section{*Correspondence:}

Tohru Yoshihisa, Graduate School of Life Science, University of Hyogo,

3-2-1, Kouto, Kamigori-cho, Ako-gun, Hyogo 678-1297, Japan

e-mail: tyoshihi@sci.u-hyogo.ac.jp
Introns are found in various tRNA genes in all the three kingdoms of life. Especially, archaeal and eukaryotic genomes are good sources of tRNA introns that are removed by proteinaceous splicing machinery. Most intron-containing tRNA genes both in archaea and eukaryotes possess an intron at a so-called canonical position, one nucleotide $3^{\prime}$ to their anticodon, while recent bioinformatics have revealed unusual types of tRNA introns and their derivatives especially in archaeal genomes. Gain and loss of tRNA introns during various stages of evolution are obvious both in archaea and eukaryotes from analyses of comparative genomics. The splicing of tRNA molecules has been studied extensively from biochemical and cell biological points of view, and such analyses of eukaryotic systems provided interesting findings in the past years. Here, I summarize recent progresses in the analyses of tRNA introns and the splicing process, and try to clarify new and old questions to be solved in the next stages.

Keywords: tRNA, intron, splicing, genome, archaea, eukaryote
Progress in bioinformatics widens our understanding of structural characteristics of tRNA genes (Lowe and Eddy, 1997; Sugahara et al., 2006, 2008; Heinemann et al., 2010; Cognat et al., 2013). Especially, recent powerful sequence analyses with the next generation sequencers accumulate an enormous amount of sequence information in tRNA genes through whole genome sequencing of non-model organisms from various evolutional clades and through metagenome analyses mostly of prokaryotic species. In these analyses, introns were found in many tRNA genes in genomes among all of the three kingdoms of life (Heinemann et al., 2010). In eubacterial genomes, and their relatives, eukaryotic organellar genomes, small numbers of tRNA genes harbor the group I intron within the anticodon region (Reinhold-Hurek and Shub, 1992; Haugen et al., 2005). These introns are spliced by a series of phosphoester transfer reactions catalyzed by intronic sequences, whose mechanism is somehow related to splicing of mRNA. On the other hand, archaeal and eukaryotic nuclear genomes have tRNA introns whose splicing is completely dependent on proteinaceous enzymes (Phizicky and Hopper, 2010; Popow et al., 2012; Hopper, 2013). In addition to normal introns, their variations have been found in both archaeal and eukaryotic genomes. Furthermore, various interesting observations have been reported on biochemical and cell biological aspects in pretRNA splicing machinery in recent years. In this review, I mainly handle issues related to these "protein-spliced" tRNA introns and their splicing machinery by emphasizing comparison between archaeal and eukaryotic systems.

\section{STRUCTURAL CHARACTERISTICS OF tRNA GENES HARBORING INTRONS}

Introns found in archaeal and eukaryotic tRNA genes are mostly inserted at one nucleotide $3^{\prime}$ to the anticodon, namely position 37/38 in the standard nomenclature (Figure 1) while introns are also inserted into other parts of tRNA genes in minor cases (see below in detail). Because intron insertion at this canonical position disrupts the anticodon stem-loop structure, its splicing is indispensable for tRNA maturation. On the other hand, the canonical intron does not seem to interrupt the overall tRNA structure (Figure 1). Indeed, pre-tRNAs with the canonical intron were shown to maintain structures of the D and T $\Psi \mathrm{C}$ arms, and the acceptor stem by chemical and enzymatic probing (Swerdlow and Guthrie, 1984; Lee and Knapp, 1985). Structural characteristics of archaeal and eukaryotic tRNA genes containing the canonical intron have some similarity: mostly, $5^{\prime}$ - and $3^{\prime}$-splice sites are set in short single-stranded segments franked by doublestranded stretches. However, close inspection of these structures reveal some difference between the two groups, which is derived from difference in strategy of splice site recognition by splicing enzymes. For splicing of pre-tRNAs, both archaebacteria and eukaryotes utilize similar sets of enzymes, namely tRNA splicing endonuclease (Sen) (Thompson and Daniel, 1990; Trotta et al., 1997; Li et al., 1998; Akama et al., 2000; Paushkin et al., 2004) and tRNA ligase (Phizicky et al., 1986; Englert and Beier, 2005; Englert et al., 2010, 2011; Popow et al., 2011, 2014). Some organisms require additional factors for the ligation step (Culver et al., 1997; Harding et al., 2008; Popow et al., 2011, 2014). Among these, splicing endonuclease is responsible for recognition of splice sites, and acts as a decoding engine of tRNA-type splice sites on various transcripts (see below in detail).

\section{INTRON-CONTAINING TRNA GENES IN ARCHAEBACTERIA}

Introns are found in every isodecoder tRNA (tRNAs with the same anticodon) genes of sequenced archaeal genomes. On an average, $\sim 15 \%$ of tRNA genes have introns in the archaeal genomes while ratio of intron-containing genes varies from $\sim 8 \%$ in Euryarchaeota to $\sim 48 \%$ in Crenarchaeota (Marck and Grosjean, 2003; Sugahara et al., 2008; Chan et al., 2011). Length of introns ranges from 11 to $129 \mathrm{nt}$, and its median for each isodecoder 


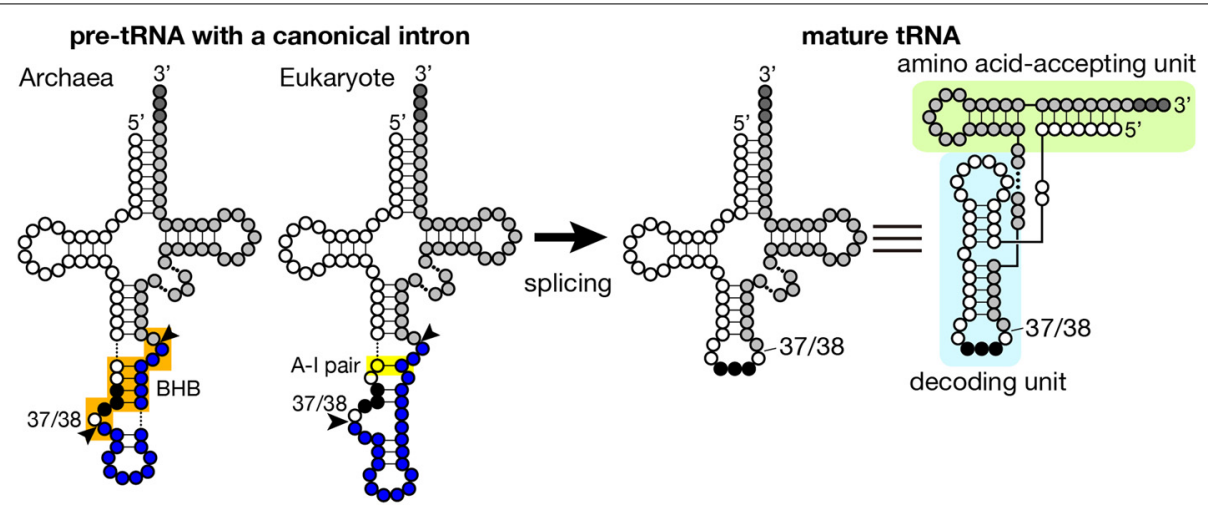

FIGURE 1 | Secondary structures of pre-tRNA and mature tRNA. Typical secondary structures of pre-tRNAs with a canonical intron (left) and mature tRNA (right) are schematically shown. White circles with three black circles, blues circles, and light gray circles represent 5'-exon, intron and $3^{\prime}$ exon of pre-tRNA, respectively. The anticodon is represented with black circles, and CCA tri-nucleotides added at the $3^{\prime}$-terminus of tRNA are depicted with dark gray circles. The BHB motif in archaeal pre-tRNA and the A-I pair in eukaryotic pre-tRNA are highlighted with orange and yellow shadow, respectively. Arrowheads represent splice sites. Mature tRNA is illustrated in two different ways. In the right most structure, decoding and amino acid-accepting units of mature tRNA are marked with light blue and light green shadow, respectively.
tRNA falls mostly in 12-25 nt except the case of tRNA-TrpCCA introns (65 nt), which nest a box C/D small RNA (Omer et al., 2000; Clouet d'Orval et al., 2001; Singh et al., 2004). The hallmark of splice sites in archaeal pre-tRNAs is the bulge-helix-bulge (BHB) motif (Kjems and Garrett, 1988; Tang et al., 2002; Marck and Grosjean, 2003), and the BHB motif is a critical determinant for recognition by archaeal splicing endonuclease (Xue et al., 2006), which consists of a 4 bp double-stranded helix flanked with two 3 nt bulges (Figure 1, shadowed with orange). In a pretRNA, the first two nucleotides of the anticodon base-pair with the intron to form a part of the central $4 \mathrm{bp}$ helix, and the two adjacent bulges provide the $5^{\prime}$ - and $3^{\prime}$-splice sites. The $5^{\prime}$ - and $3^{\prime}$-splice sites may exist as independent entities, such as $\mathrm{hBH}$ and $\mathrm{HBh}^{\prime}$ motifs, in which splice sites are flanked by two short helices, in certain archaeal species (see non-canonical splice sites in Figure 3) (Marck and Grosjean, 2003). This secondary structure requirement in the $\mathrm{BHB}$ motif restricts a part of the primary sequence of the intron while quite large variations in sequence are accepted in the other parts of the intron.

Because of this transplantable nature of the splice sites, introns are also found at non-canonical positions of tRNAs, such as 20/21, 22/23, 25/26, 29/30, 30/31, 45/46, 53/54, 56/57, 59/60, etc., in some archaeal genomes (Figures 2A, 3). Especially, Crenarchaeota and Nanoarchaeota genomes are rich sources of non-canonical introns. In an extreme case, intron is inserted at position $3 / 4$ in certain Thermoproteales tRNAs (Sugahara et al., 2008). The non-canonical intron is sometimes accompanied by the canonical and other non-canonical introns in the same tRNA genes. For example, a tRNA-ProugG gene in Pyrobaculum islandicum has two non-canonical introns inserted at position 25/26 and 56/57 in addition to a canonical intron (Figure 3B) (Sugahara et al., 2007). Splice sites of these non-canonical introns are found not only in the $\mathrm{BHB}$ motif but also in the $\mathrm{HBh}^{\prime}$ and/or $\mathrm{h}^{\prime} \mathrm{BH}$ motifs (Marck and Grosjean, 2003).

Furthermore, tRNA genes consist of separated transcriptional units have been identified in Crenarchaeal genomes

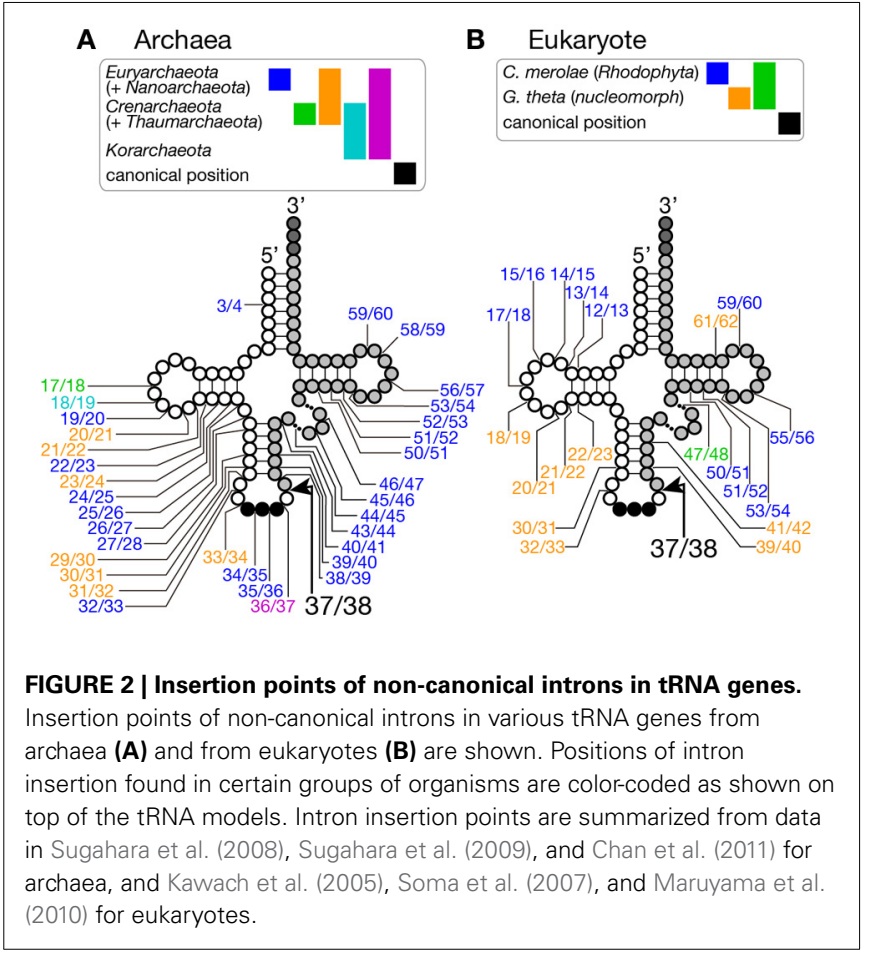

(Randau et al., 2005b,c). "Split tRNA genes" were first reported in Nanoarchaeum equitans: in this organism, tRNA-His ${ }_{G U G}$ is encoded by two gene fragments corresponding to $5^{\prime}$ - and $3^{\prime}$-halves separated at position $37 / 38$ in the anticodon loop (Figure 3C). The $5^{\prime}$ - and $3^{\prime}$-halves are transcribed from their own promoters with the trailer and leader sequences whose portions are complementary to each other. A predicted secondary structure of the hybridized fragments is highly similar to that of a pre-tRNA harboring a canonical intron with a relaxed $\mathrm{BHB}$ motif, like a pre-tRNA received a cleavage at a loop in the intron. 


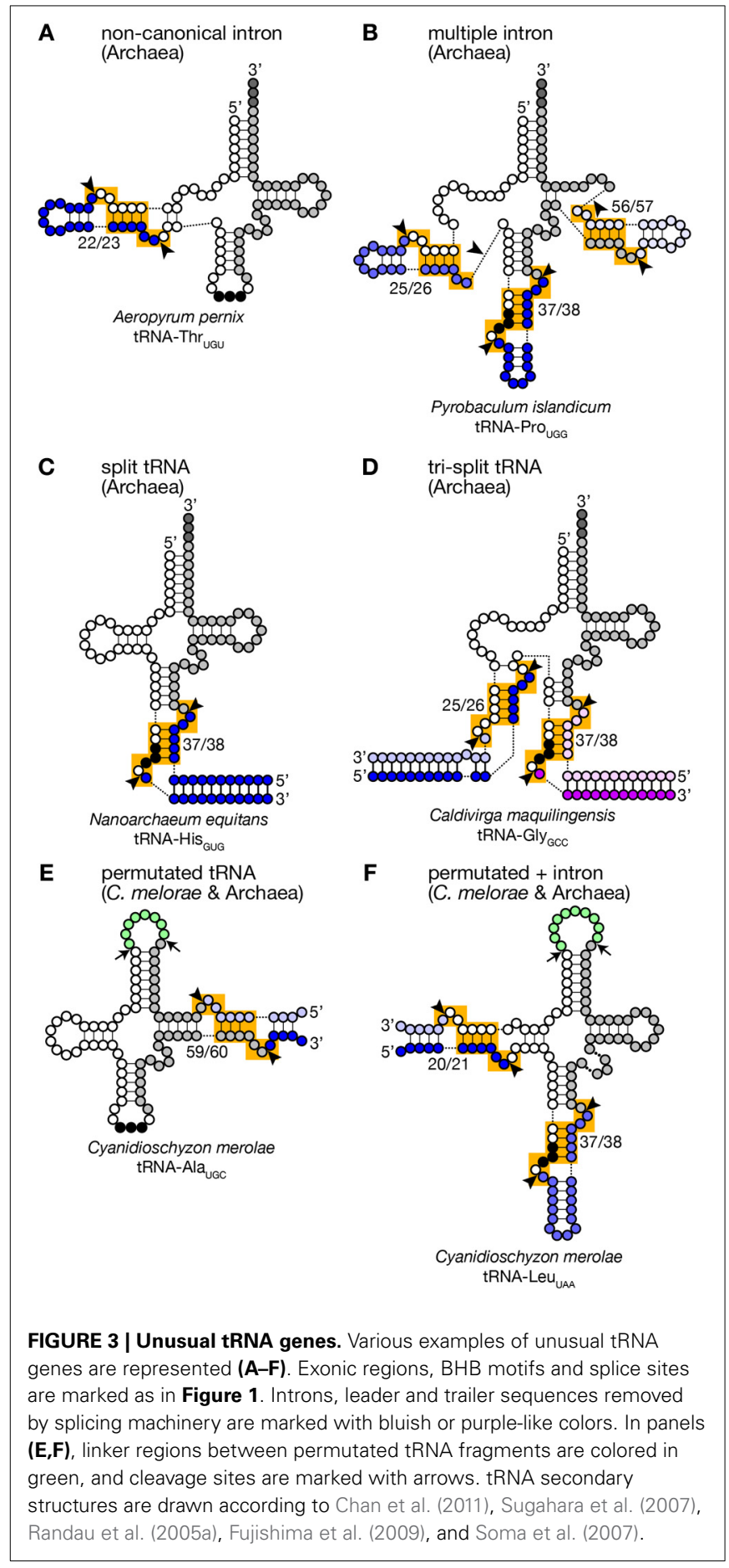

Indeed, RT-PCR analysis revealed that the split tRNA fragments are transcribed, and the transcripts are joined to form mature and functional tRNAs in vivo, indicating that trans-splicing is operating in N. equitans (Randau et al., 2005b,c). Further in vitro analyses revealed that splicing endonuclease from $N$. equitans can recognize this "pre-tRNA" complex and cleave off the trailer and leader sequences at the precise positions, and the resulting RNA is suitable for ligation by tRNA ligase (Randau et al., 2005a;
Tocchini-Valentini et al., 2005). An interesting case in this organism is that tRNA-Glu CUC $_{\text {and }}$ RNA-Glu UUC $_{\text {, }}$ isodecoder tRNAs for the same amino acid, are produced from two different $5^{\prime}$ halves and one common $3^{\prime}$-half by trans-splicing (Randau et al., 2005b). Probably, trans-splicing contributes to saving genomic space to be assigned to tRNAs and to increasing probability to have more isodecoders especially in the case of N. equitans, a parasitic bacterium with massive genome reduction (Makarova and Koonin, 2005). Or trans-splicing may be an evolutionary remnant of the ancient form of tRNA gene organization (see below).

There are more complicated cases. In Caldivirga maquilingensis, tRNA-Gly isodecoders with anticodons, CCC, UCC, and GCC, are formed by combinations of up-to three out of five independent transcripts through trans-splicing (Figure 3D) (Fujishima et al., 2009; Sugahara et al., 2009). While tRNAGlyCCC is made from the $5^{\prime}$ - and $3^{\prime}$-halves covering 1-37 and 3873 regions, respectively, like the case of $N$. equitans $\mathrm{tRNA}-\mathrm{Glu}_{\mathrm{CUC}}$, the other two are joined from the 1-25 fragment common for the two, either one of the two specific fragments covering 26-37 with the anticodons, and the $3^{\prime}$-half used for all of the three tRNAGly isodecoders. Most of splits in the separated tRNA genes are located at canonical position (37/38) while those are at position 29/30 of tRNA-AlaCGC and tRNA-AlaUGC, and at 25/26 of tRNAGlu $_{\mathrm{UUC}}$ in the C. maquilingensis genome. N. equitans and some Staphylothermus genomes harbor split tRNA-Lys $\mathrm{CUU}$ at position 30/31 (Fujishima et al., 2009; Chan et al., 2011). For the tri-split tRNA genes, splits are usually combination between one canonical position and one or more non-canonical positions (Fujishima et al., 2009).

\section{INTRON-CONTAINING tRNA GENES IN EUKARYOTES}

In eukaryotic genomes, most of intron-containing tRNA genes have their introns at the canonical position with length of 6$133 \mathrm{nt}$ (Lowe and Chan, 2011). Because the nuclear genome of a eukaryote contains multiple tRNA genes encoding an isodecoder tRNA to allow sufficient supply of the tRNA, the number of tRNA genes in a eukaryotic genome does not correspond to that of sequence variations of tRNAs. Ratios of introncontaining tRNA genes vary significantly among eukaryotes: only 39 out of 1068 tRNAs genes (3.7\%) have an canonical intron in Strongylocentrotus purpuratus (sea urchin) while in the infectious yeast, Cryptococcus neoformans, 132 out of 143 tRNA genes (92\%) have an intron (Lowe and Chan, 2011). Whether all the predicted introns in eukaryotic genomes are spliced properly has not been fully confirmed. However, the yeast, Saccharomyces cerevisiae, which has 61 intron-containing genes encoding 10 different isodecoder tRNAs, can splice all the pre-tRNAs with introns by the single splicing endonuclease, the Sen complex, and this is also true in human (Trotta et al., 1997; Paushkin et al., 2004).

A clear difference between eukaryotic and archaeal introns in tRNA genes is that eukaryotic introns do not have clear local motifs specifying splice sites as described on archaeal introns (Figure 1). Rather, eukaryotic splicing endonuclease is considered to recognize splicing sites of pre-tRNAs by ruler-mechanism, in which the Sen complex measures distance between the body of tRNA and the splice sites, and this allows more flexible sequence selection around splicing sites in eukaryotic pre-tRNAs 
(Greer et al., 1987; Reyes and Abelson, 1988). Analyses of the secondary and tertiary structures of eukaryotic pre-tRNAs indicate that many pre-tRNAs have splice sites in single-stranded regions adjacent to double-stranded stretches, suggesting a eukaryotic site-recognition strategy similar to that of archaeal enzyme to some extent (Greer et al., 1987; Reyes and Abelson, 1988). Indeed, eukaryotic splicing endonuclease can recognize and splice archaeal-type pre-tRNAs with a BHB motif, meaning that eukaryotic splicing endonuclease has ability to read local structural features of substrate RNAs (Fabbri et al., 1998; Di Segni et al., 2005). However, close inspection of substrate specificity in tRNA splicing of S. cerevisiae and Xenopus extracts with artificial substrates demonstrated that double-stranded regions formed between the anticodon loop and the intronic sequence are not prerequisite to splicing (Reyes and Abelson, 1988). Thus, for our complete understanding of splice site properties essential for Sen recognition, we need to wait until structures of complexes between eukaryotic splicing endonuclease and various pre-tRNAs are solved.

Although short insertions can be found in D or T $\Psi \mathrm{C}$ arms of various eukaryotic tRNA genes, such insertions are mostly found one of many synonymous tRNA genes on a genome. Thus, such genes are supposed to be pseudogenes, and non-canonical introns in eukaryotic genomes are supposed to be rare. However, it was reported that nuclear remnants of enslaved algae, nucleomorphs, in cryptophytes and chlorarachniophytes harbor tRNA genes with non-canonical introns in the $\mathrm{D}$ and T $\Psi \mathrm{C}$ arms in addition to non-canonical positions in the anticodon stem-loop (Kawach et al., 2005; Maruyama et al., 2010). For example, the nucleomorph genome of Guillardia theta contains 9 tRNA genes (including one pseudogene) with insertions with length from 3 to $24 \mathrm{nt}$ at non-canonical positions (Figure 2B). Interestingly, their excision, including that of the $3 \mathrm{nt}$ intron in the T $\Psi \mathrm{C}$ arm

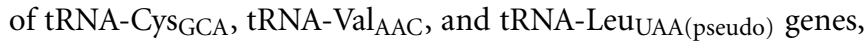
was confirmed by sequencing of RT-PCR products of the algal RNAs (Kawach et al., 2005) while we still do not know how these non-canonical introns, especially extremely short ones, are spliced. Moreover, 4 tRNA genes, such as tRNA-Phe ${ }_{\mathrm{GAA}}$ genes, of this organism harbor two introns, and 2 tRNA genes, elongator tRNA-Met (tRNA-eMet) and tRNA-Cys $s_{\mathrm{GCA}}$, do three introns, like the case of Crenarchaeal tRNA genes. Similar non-canonical introns are also found in the nuclear genome of a red algae Cyanidioschyzon merolae (Soma et al., 2007). Therefore, certain eukaryotic splicing endonucleases have ability to recognize splice sites inserted at non-canonical positions. In this point of view, splicing machinery of $C$. merolae seems to have more archaea-like characteristics, and BHB motifs seem to be critical determinants of substrate selection for this splicing endonuclease (Soma et al., 2013).

Another unusual tRNAs that were first reported on the C. merolae genome are permutated tRNAs, in which normal $5^{\prime}$ and $3^{\prime}$-termini are bridged with a short loop, and their $3^{\prime}$-half is positioned upstream of the $5^{\prime}$-half (Soma et al., 2007). Six tRNAs such as tRNA-Gln $\operatorname{lnG}_{\text {G }}$ in $C$. merolae have its $5^{\prime}$-leader sequence before position 38 and its $3^{\prime}$-trailer after position 37. Atypical $5^{\prime}$ - and $3^{\prime}$-termini are also introduced in the D arm of tRNA-

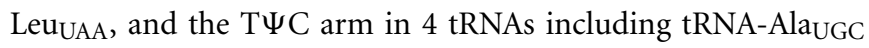

(Figures 3E,F). RT-PCR analyses revealed that these permutated tRNA transcripts are indeed converted into mature and functional tRNAs via circular intermediates (Soma et al., 2007, 2013). The new $3^{\prime}$-trailer and $5^{\prime}$-leader sequences have ability to basepair and produce a splice site-like structure with a BHB motif similar to that of archaeal split tRNA transcripts (Randau et al., 2005b). Thus, splicing machinery is thought to cleave the extensions from the permutated pre-tRNAs and joined separated ends of revers-oriented exons while true $5^{\prime}$ - and $3^{\prime}$-termini of the mature tRNAs are thought to be generated by the action of terminal processing enzymes, such as RNase P and tRNase Z. Similar permutated tRNA genes have been found in other single-cell algae, such as prasinophytes and nucleomorphs in cryptophytes (Maruyama et al., 2010). Permutated tRNA genes are not limited to eukaryotes. An archaea, Thermofilum pendens, also has permutated tRNA-Tyr ${ }_{\mathrm{GUA}}$ and initiator tRNA-Met (tRNA-iMet) genes with new $5^{\prime}$ - and $3^{\prime}$-termini formed in the T $\Psi \mathrm{C}$ arm (Chan et al., 2011). However, distribution of permutated tRNA genes is so far limited in only certain clades of eukaryotes and archaea.

\section{SPLICING MACHINERY SPLICING ENDONUCLEASE}

As mentioned previously, splicing endonuclease is a search engine for tRNA-type splices sites among various transcripts produced by an organism. One splicing endonuclease, or an endonuclease complex, in an organism cleaves both the $5^{\prime}$ - and $3^{\prime}$-splice sites of an intron to produce two $5^{\prime}-\mathrm{OH}$ termini on the intron and $3^{\prime}$-exon, and two $2^{\prime}, 3^{\prime}$-cyclic phosphate termini on the $5^{\prime}$-exon and intron, meaning that the reaction is phosphoester transfer but not hydrolysis. The archaeal endonucleases are classified into three types from subunit organization; $\alpha_{4}, \alpha_{2}$ and $\alpha_{2} \beta_{2}$ (TocchiniValentini et al., 2005; Calvin and Li, 2008). The archetypal configuration of the enzymes is supposed as an $\alpha_{4}$ homotetramer. The crystallographic analysis of EndA from Methanococcus jannaschii revealed that this tetrameric enzyme consists of a 2-fold but not 4-fold symmetric structure, where two subunits are mainly used to build two reaction centers for splice site cleavage, and the other two are used as structural components to position the catalytic subunits in an appropriate spatial arrangement for accepting the BHB motif (Lykke-Andersen and Garrett, 1997; Li et al., 1998). The $\alpha_{2}$ type is a kind of "a dimer of dimers," in which two tandemly duplicated endonuclease units in a polypeptide act as a catalytic unit and a structural unit, respectively (Kleman-Leyer et al., 1997; Li and Abelson, 2000). The resulting dimer shows a configuration similar to that of $\alpha_{4}$ enzymes. The $\alpha_{2} \beta_{2}$ type is also a derivative of $\alpha_{4}$ (Mitchell et al., 2009; Yoshinari et al., 2009). Gene duplication and different requirements for catalytic and structural subunits have led sequence divergence of the two subunits. Appearance of certain subunit types is well correlated with phylogenetic relation of archaebacteria and, more importantly, with diversity of tRNA introns and splice sites (Tocchini-Valentini et al., 2005; Calvin and Li, 2008). Species in Euryarchaeota and Korarchaeota essentially have $\alpha_{4}$ - or $\alpha_{2}$-type splicing endonucleases, while those in Nanoarchaeota, Thaumarchaeota, and Crenarchaeota have $\alpha_{2} \beta_{2}-$ type enzymes. Interestingly, the latter group of archaea is rich in tRNA genes with introns: most unusual tRNA genes, such as 
those with non-canonical introns, with multiple introns or with permutated configuration, are found in these organisms (Marck and Grosjean, 2003; Sugahara et al., 2008; Chan et al., 2011). Some of the splice sites in these tRNA genes comprise expanded formats of the $\mathrm{BHB}$, such as $\mathrm{hBH}$ or $\mathrm{HBh}^{\prime}$ (Tocchini-Valentini et al., 2005). On the other hand, Euryarchaeota, mostly possessing $\alpha_{4}$ - or $\alpha_{2}$-type enzymes, has low ratios of tRNA genes with introns (less than 10\%), and these tRNA genes have only one intron with the BHB motif at the canonical position. Therefore, subunit organization of splicing endonuclease seems to be a determinant for the substrate spectrum of the enzyme; strict to the BHB motif at the canonical position in $\alpha_{4}$ and $\alpha_{2}$ enzymes, and lenient in $\alpha_{2} \beta_{2}$ enzymes.

Eukaryotic splicing endonuclease consisting of four subunits, namely Sen2, Sen34, Sen54, and Sen15, was first identified in the yeast S. cerevisiae (Rauhut et al., 1990; Trotta et al., 1997). Among the four subunits, Sen 2 and Sen 34 have catalytic centers that are responsible for cleavage of $5^{\prime}$ - and $3^{\prime}$-splice sites, respectively. On the other hand, Sen54 was reported to interact with the D-arm of substrate pre-tRNAs and to position catalytic subunits away from the body of tRNA with appropriate distances (Trotta et al., 2006; Xue et al., 2006). Human endonuclease contains homologs of all the 4 Sen proteins found in S. cerevisiae (Paushkin et al., 2004), and Arabidopsis thaliana also possesses Sen2 and Sen34 homologs (Akama et al., 2000). There is appreciable conservation among these eukaryotic Sen 2 and Sen34 subunits, and archaeal endonucleases, indicating the same evolutional origin of splicing machinery. The human Sen complex also contains Clp1 (hClp1) (Paushkin et al., 2004; Weitzer and Martinez, 2007). Clp1 was first identified as a component of the cleavage factor II for polyadenylation of pre-mRNAs (de Vries et al., 2000), and then re-identified as an in vitro kinase for tRNA exons when searching for an enzyme phosphorylating siRNAs displaying a $5^{\prime}-\mathrm{OH}$ group (Figure 4) (Weitzer and Martinez, 2007). Divergence of subunit organization is greater in eukaryotic endonuclease than in archaeal enzymes, and eukaryotic splicing endonucleases have the ability to cleave both eukaryotic and archaeal types of splice sites as described above. Thus, it can be said that subunit organization diversity is, again, correlated with local splice site variability even between different kingdoms of life. Although direct relation between repertoires of intron-containing tRNA genes and subunit configuration of splicing endonucleases among eukaryotes has not been analyzed extensively, one interesting example is C. merolae. Bioinformatic analysis successfully identified genes for Sen2, Sen34, and Sen54 but failed to identify any gene or gene fragment that may encodes the fourth essential subunit Sen 15 (Soma et al., 2013). In addition, yeast two-hybrid analyses could not identify other proteins that interact with either one of the three C. merolae Sen proteins, suggesting that the Sen complex of this organism may consist of 3 but not 4 subunits. Although further study is needed, such unique subunit organization in $C$. merolae may be related to existence of tRNA genes with non-canonical introns and permutated tRNA genes in this organism.

\section{ENZYMES CATALYZING LIGATION STEPS}

Excised tRNA exons are joined by tRNA ligase. There are two completely different chemical pathways of ligation classified from the origin of the phosphate bridging the $5^{\prime}$ - and $3^{\prime}$-exons:

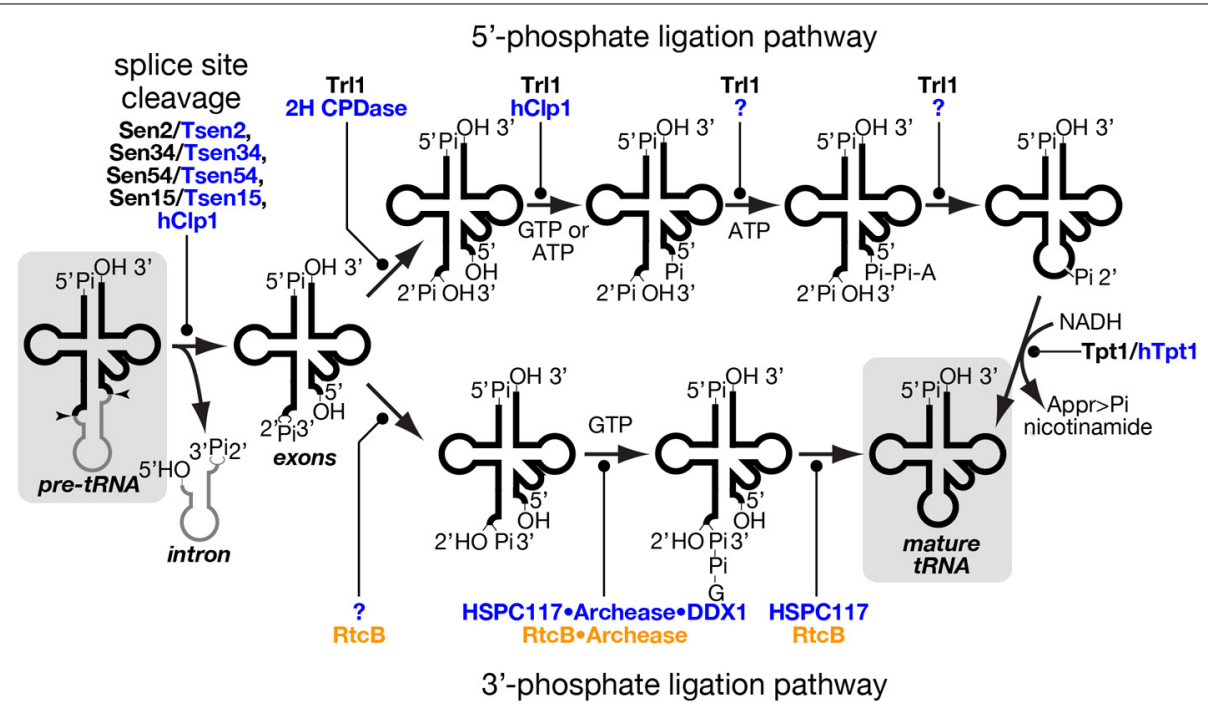

FIGURE 4 | tRNA splice site cleavage and two pathways of tRNA ligation. Series of chemical reactions in splice site cleavage of pre-tRNA (left), the 5'-phosphate ligation pathway (upper), and the $3^{\prime}$-phosphate ligation pathway (lower) are shown schematically. Proteins involved in individual reactions are also shown, and unidentified factors are denoted by question marks. Those proteins of yeast, mammal and prokaryotes are color-coded with black, blue and orange, respectively. In the 5'-phosphate ligation pathway, yeast $\operatorname{Tr} 11$ uses GTP as a phosphate donor while hClp1 in the mammalian system uses ATP instead of GTP for $5^{\prime}$-phosphorylation of the $3^{\prime}$-exon. Although a mammalian enzyme(s) catalyzing the last two steps of this pathway is still missing, such an enzyme was found in lancelet. In the $3^{\prime}$-phosphate ligation pathway, the mammalian protein responsible for $2^{\prime}-3^{\prime}$ cyclic phosphodiesterase in the HSPC117 complex was not fully identified, but eubacterial RtcB, an HSPC117 homolog, was demonstrated to possess this activity (Tanaka and Shuman, 2011). The starting material, pre-tRNA, and the end product, mature tRNA, are shadowed. Appr $>\mathrm{Pi}$ represents ADP-ribose $1^{\prime \prime}-2$ " cyclic phosphate. 
one is the $5^{\prime}$-phosphate ligation pathway and the other is the $3^{\prime}$-phosphate ligation pathway (Figure 4) (Popow et al., 2012). At the first step, ligation systems need to open the $2^{\prime}, 3^{\prime}$-cyclic phosphodiester on the $5^{\prime}$-exon. The $5^{\prime}$-phosphate ligation pathway produces the $3^{\prime}$ terminus with $2^{\prime}$-phosphate and $3^{\prime}-\mathrm{OH}$ (Phizicky et al., 1986; Sawaya et al., 2003; Wang and Shuman, 2005) while the $3^{\prime}$-phosphate ligation pathway does that with $2^{\prime}-\mathrm{OH}$ and $3^{\prime}$-phosphate (Popow et al., 2011; Chakravarty et al., 2012). The former does not use the $2^{\prime}$-phosphate but a new phosphate derived from a nucleotide triphosphate to form a bridge between the two exons (Westaway et al., 1993), while the latter utilizes the $3^{\prime}$-phosphate left on the $5^{\prime}$-exon (Popow et al., 2011; Chakravarty et al., 2012). In both cases, the phosphorylated exon is further activated by nucleotidylation, and then ligated to its counterpart using the nucleotide monophosphate as a leaving group (Phizicky et al., 1986; Westaway et al., 1993; Popow et al., 2011; Chakravarty et al., 2012). In the case of the $5^{\prime}$-phosphate ligation pathway, the $2^{\prime}$-phosphate left at the splice junction must be removed after the ligation (Culver et al., 1997; Harding et al., 2008).

\section{$5^{\prime}$-phosphate ligase}

The $5^{\prime}$-phosphate ligation pathway has been found widely in fungi and plants. It also operates in lancelet but is most probably absent in mammalian cells (Lappe-Siefke et al., 2003; Harding et al., 2008; Englert et al., 2010; Popow et al., 2011). tRNA ligase for $5^{\prime}$-phosphate ligation, Trl1/Rlg1, was first identified in $S$. cerevisiae and then in A. thaliana through biochemical analysis (Phizicky et al., 1986; Englert and Beier, 2005). Trl1 homologs are widely found in the genomes from fungi through diatoms to angiosperms but are absent in animals (Englert and Beier, 2005; Wang et al., 2006). Trl1 homologs catalyze all the chemical reactions of exon ligation except for removal of the 2 '-phosphate at the splice junction, and consist of three domains covering three enzymatic activities; adenylate synthetase/RNA ligase (ASTase), polynucleotide kinase (PNKase), and 2', 3'cyclic phosphodiesterase (CPDase) in this order (Xu et al., 1990; Sawaya et al., 2003). CPDase opens the $2^{\prime}, 3^{\prime}$-cyclic phosphate on the $3^{\prime}$-terminus of the $5^{\prime}$-exon, and PNKase phosphorylates the $5^{\prime}$-terminus of the $3^{\prime}$-exon with GTP. By transferring an AMP moiety to this $5^{\prime}$-terminus from ATP, ASTase activates this end and allows ligation between the two exons (Figure 4, upper). During this terminal activation, the AMP moiety is first covalently attached to the ASTase domain and then transferred to the substrate. Although splicing endonuclease is responsible for primary recognition of splice sites, yeast $\operatorname{Trl} 1$ has the ability to interact with introns in pre-tRNAs (Tanner et al., 1988) and with an intron-containing precursor of its non-tRNA substrate, HAC1 mRNA acting as a key component for the unfolded protein response (Sidrauski et al., 1996; Mori et al., 2010). The $2^{\prime}$-phosphate left at the splice junction is finally removed by $2^{\prime}$-phosphotransferase, or Tpt1 in S. cerevisiae (Culver et al., 1997). This reaction is unique in that $2^{\prime}$-phosphate is transferred to NADH to yield ADP-ribose $1^{\prime \prime}-2^{\prime \prime}$ cyclic phosphate and nicotinamide (Figure 4, right most part). Indeed, this enzyme is essential for yeast growth, indicating that the $2^{\prime}$-phosphate is toxic for protein translation.
Although the $5^{\prime}$-phosphate ligation activity was once demonstrated in the nuclear extract of HeLa cells (Zillmann et al., 1991), a vertebrate $5^{\prime}$-phosphate ligase has not yet been identified. A lancelet Branchiostoma floridae has a complete set of enzymes for this ligation pathway; adenylate synthetase/RNA ligase activities and the other two activities for the tRNA ligation are encoded by two independent genes (Englert et al., 2010). In vertebrates, several polypeptides in different complexes can catalyze some of the individual reaction steps responsible for a putative $5^{\prime}$-phosphate ligation. First, in vitro phosphorylation of the $5^{\prime}$-terminus of the $3^{\prime}$-exon can be done by hClp1 kinase associated with the human Sen complex (Weitzer and Martinez, 2007). Second, mammalian genomes harbor genes for $2 \mathrm{H}$ CPDase, which can open the $2^{\prime}, 3^{\prime}$-cyclic phosphodiester bond at the $3^{\prime}$-terminus of the $5^{\prime}$-exon to produce $3^{\prime}$-OH and $2^{\prime}$-phosphate groups, and the CPDase domain of fungal and plant Trl1 is classified as this family (Popow et al., 2012). Third, mammals possess $2^{\prime}$-phosphotransferase activities for RNA substrates. However, both mouse $2 \mathrm{H}$ CPDase and Tpt1 (Cnp1 and Trpt1, respectively) are non-essential for viability (Lappe-Siefke et al., 2003; Harding et al., 2008). Especially, Trpt1-knockout mice, which completely lacks $2^{\prime}$-phosphotransferase activity, were demonstrated not only to translate Tyr-rich proteins efficiently, which require appropriate splicing of the $\mathrm{tRNA}-\mathrm{Tyr}_{\mathrm{GUA}}$ intron but also to show no defects in splicing of XBP1 mRNA (Harding et al., 2008), which undergoes tRNA-type unconventional splicing in the cytoplasm upon unfolded protein response, like yeast HAC1 mRNA (Yoshida et al., 2001; Calfon et al., 2002). Therefore, even if vertebrates have the complete set of the enzymes for the $5^{\prime}$-phosphate ligation pathway, this pathway seems to contribute to only a small, if any, part of RNA splicing.

\section{3'-phosphate ligase}

In vertebrates, a tRNA ligase activity utilizing the $2^{\prime}, 3^{\prime}$-cyclic phosphate to bridge the tRNA exons has been known for decades, but the enzyme responsible for this reaction was found only a few years ago (Filipowicz and Shatkin, 1983; Laski et al., 1983; Popow et al., 2011). Indeed, the $3^{\prime}$-phosphate ligase HSPC117 is a main player for tRNA splicing in mammals, and HSPC117 homologs are found in vertebrates, lancelets, insects, protozoa, algae etc., but not in fungi or angiosperms, which possess Trl1 homologs (Popow et al., 2011, 2012 for a review). Although HSPC117 forms a large complex with DDX1 (RNA helicase), CGI-99, FAM98B, and ASW, whether all of these subunits are involved in tRNA ligation is not known completely (see below). Homologs of HSPC117, whose name in prokaryotes is RtcB, exist widely in archaeal genomes where no Trl1 homologs exist (Englert et al., 2011). Interestingly, RtcB genes are also found in eubacterial genomes despite the fact that eubacteria do not have tRNA genes with introns removed by protein-assisted splicing. And eubacterial RtcB genes are located in operons with genes encoding RNA $3^{\prime}$-phosphate cyclase, which transforms a $3^{\prime}$-phosphate of an RNA molecule into a $2^{\prime}, 3^{\prime}$-cyclic phosphate (Tanaka and Shuman, 2011). It is suggested that the set of enzymes is used to repair damaged tRNAs whose anticodon loop is endonucleolytically cleaved. These facts may indicate that the $3^{\prime}$-phosphate ligation pathway 
is a predominant and probably primordial pathway for tRNA ligation.

As mentioned above, HSPC117/RtcB also has adopted nucleotidylation to activate an exon terminus, but the ligase transfers a GMP moiety, instead of AMP, to the $3^{\prime}$-terminus of the $5^{\prime}$ exon (Figure 4, lower) (Chakravarty et al., 2012; Popow et al., 2014). During the reaction, the GMP moiety is covalently attached to the ligase, and this activation step seems to be rate limiting to the overall ligase cycle in eubacterial RtcB (Chakravarty et al., 2012). This is also true in human ligase HSPC117, and these facts suggest that some factor(s) is required for efficient turnover of $3^{\prime}$-phosphate ligase. Bioinformatic search for clusters of eukaryotic orthologous groups conserved in the same model organisms as RtcB and biochemical confirmation revealed that a small protein named "archease" enables HSPC117 to catalyze multiple-rounds of ligation reaction (Popow et al., 2014). Detailed biochemical analyses revealed that archease specifically enhances GMP transfer from GTP to HSPC117 protein but not that from the HSPC117-GMP adduct to the $3^{\prime}$-terminus of RNA substrates. Furthermore, this step also requires another activity catalyzed by DDX1, an RNA helicase within the HSPC117 complex. The implication of DDX1 ATPase provides evidence for molecular mechanism of ATP hydrolysis in the mammalian ligation reaction (Popow et al., 2011, 2014). Interestingly, involvement of archease in tRNA processing was first reported on $\mathrm{m}^{5} \mathrm{C}$ formation of tRNA in archaea Pyrococcus abyssi, where archease enhances substrate specificity of $\mathrm{m}^{5} \mathrm{C}$ methyltransferase and prevents it from aggregation probably by acting as a chaperone (Auxilien et al., 2007). Recently, archease was also demonstrated to catalyze efficient activation of archaeal RtcB where it enhances all nucleotidyl transfer steps in the $3^{\prime}$-phosphate ligation, including GMP transfer to RNA molecules (Desai et al., 2014).

\section{DIVERSITY OF SPLICING MACHINERY IN EUKARYOTES; INTRACELLULAR LOCALIZATION AND FUNCTION}

As mentioned above, eukaryotic splicing factors are more complex than those of archaea. According to this complexity, the splicing factors in various eukaryotes have acquired diversity in several aspects. One interesting aspect is the place of splicing in eukaryotic cells. Despite the functional and structural conservation of eukaryotic splicing endonucleases, their intracellular localization is divergent among organisms. Splicing endonucleases in vertebrates show expected localization: they are mainly found in the nucleus (De Robertis et al., 1981; Paushkin et al., 2004). Thus, it has been suggested that pre-tRNAs are spliced in the nucleus and only matured tRNAs are supplied to the cytoplasm. On the other hand, in S. cerevisiae, splicing of pretRNAs proceeds in the cytoplasm: tRNA splicing endonuclease was found to associate with mitochondrial surface, and this association is required for proper function of the enzyme (Yoshihisa et al., 2003, 2007). Later, the other enzymes required for completing splicing were also demonstrated to localize in the cytoplasm (Mori et al., 2010). It is to be noted that cytoplasmic localization of the Sen complex itself is not essential for pre-tRNA splicing for the yeast. When all the Sen subunits are expressed in the nucleus, pre-tRNAs are spliced normally (Dhungel and Hopper, 2012). These findings suggest that eukaryotic cells can tolerate drastic alteration of the place of tRNA splicing.

Although we have not obtained a complete view of tRNA splicing machinery in plant cells, some subunits of Sen proteins and tRNA ligase from A. thaliana were revealed to have multiple destination signals (Englert et al., 2007). When expressed as GFP fusions, AtSen2 and AtSen1 localized to the nucleus and mitochondria while AtTrl1 did to the nucleus and chloroplasts. Especially in the case of AtTrl1, alternative translational initiation may produce two isoforms; one from the most up-stream AUG is targeted to chloroplasts and the other from downstream AUG is to the nucleus (Englert et al., 2007). Thus, the nucleus may be the primary site of pre-tRNA splicing of nuclear encoded tRNAs in plant cells. On the other hand, one report provided a piece of evidence against this notion: unspliced pre-tRNAs accumulated when tRNA export from the nucleus was suppressed by RNAimediated knock-down of the tRNA export carrier, Exportin$\mathrm{t}$ /Paused (Park et al., 2005). This situation is quite similar to that of $S$. cerevisiae, where disruption of LOS1, which encodes the yeast homolog of Exportin-t, leads accumulation of pre-tRNAs because of their sequestration from cytoplasmic splicing enzymes (Sharma et al., 1996; Yoshihisa et al., 2003). What is the role of mitochondrial or chloroplastic splicing enzymes in plants? Since there are no tRNA genes harboring eukaryote-archaea type introns in mitochondria and chloroplasts, plant splicing enzymes in these organelles should process a different type(s) of RNAs.

Evolution of eukaryotes also has hooked extra functions up to splicing machinery. As mentioned above, the yeast Sen complex can be transplanted from mitochondria to the nucleus without major defects in tRNA splicing. However, partial deletion of the mitochondrial targeting signal in Sen54 leads temperature sensitivity in yeast growth, and transplantation of the whole Sen complex to the nucleus compromises growth and rRNA maturation (Yoshihisa et al., 2003; Dhungel and Hopper, 2012). Thus, the yeast splicing endonuclease should have another essential function in the cytoplasm. Human splicing endonuclease activity also may have an extra function(s) other than pretRNA splicing. Mutations in human SEN2, SEN34, and SEN54 (TSEN2, TSEN34, and TSEN54 respectively) lead to pontocerebellar hypoplasia, which causes specific neurodegenerative disorders including hypoplasia of the cerebellum and the ventral pons, despite the fact that tRNA splicing is essential for every cell in the human body (Budde et al., 2008; Namavar et al., 2011). Similar phenotypes were observed when a SEN54 homolog was knocked down in zebrafish (Kasher et al., 2011). Interestingly, this disease is also caused by mutations of mitochondrial arginyltRNA synthetase (Edvardson et al., 2007; Namavar et al., 2011). Although targets of human Tsen in the pontocerebellar cells related to this disease have not been identified so far, these facts suggest that Tsen has some neuronal cell specific function, other than usual tRNA splicing, through collaboration with mitochondrial arginyl-tRNA synthetase, another tRNA-related factor. Probably, because of their relaxed substrate recognition and expansion of repertoires of transcripts in eukaryotic cells, the Sen complexes from various eukaryotes may have adopted abilities to process and/or degrade various substrates in addition to intron-containing pre-tRNAs. Mutations in vertebrate 
Clp1 were also found to cause neurodegenerative phenotypes, such as motor-sensory defects, cortical dysgenesis and microcephaly, like the case of Tsen mutants (Hanada et al., 2013; Karaca et al., 2014; Schaffer et al., 2014). Mouse Clp1-K127A (kinase-dead) and hClp1-R140H (disease-related) compromise both pre-tRNA cleavage and 5'-RNA kinase activities in vitro while they specifically affect neuronal cells in vivo in mouse and human, respectively (Hanada et al., 2013; Karaca et al., 2014). Similar phenotypes were seen in CLP1 mutants of zebrafish (Schaffer et al., 2014). The above facts suggest that, in vivo, residual activities of these Clp1 mutant proteins cannot complete tasks required in the neuronal cells while they can provide enough tRNA splicing ability in other cell types. Although fundamental functions of mammalian Clp1, as a subunit of the Sen complex or as a component of Cleavage Factor II generating mRNA $3^{\prime}$-ends, are carried out in the nucleus, some reports predict an extra-function in the cytoplasm. As mentioned before, hClp1 also acts as a $5^{\prime}$-kinase for siRNAs (Weitzer and Martinez, 2007). Phosphorylation of artificial siRNAs supplied from the outside of the cells may occur in the cytoplasm because only phosphorylated double stranded siRNAs are loaded to Ago proteins to yield RNA-induced silencing complexes in the cytoplasm while double stranded RNA import across the nuclear envelope has not been known (Nykänen et al., 2001; Ameres and Zamore, 2013). Indeed, Tsen-hClp1 can be purified from the cytosolic fraction (Weitzer and Martinez, 2007; Karaca et al., 2014).

High-order functions are also postulated for mammalian $3^{\prime}$-phosphate ligase. The HSPC117 complex was independently isolated as one of the components that allow axonal transport of mRNAs in neurons, suggesting that the HSPC117 has another function in the cytoplasm (Kanai et al., 2004). Indeed, the HSPC117 complex was recently found to shuttle between the nucleus and the cytoplasm (Pérez-González et al., 2014). A versatile RNA helicase DDX1 in this complex may account for such functions related to mRNA dynamics. As discussed above, both $5^{\prime}$-phosphate and $3^{\prime}$-phosphate tRNA ligases may also act as healing-sealing enzymes for damaged tRNAs.

\section{PHYSIOLOGICAL MEANINGS TO HAVE AN INTRON IN A tRNA GENE \\ PHYSIOLOGICAL FUNCTION OF INTRON IN PRE-tRNA DURING ITS MATURATION}

The tRNA intron is indeed an obstacle for tRNA's function, and seems to exist just to be removed after transcription. Why do organisms need to keep the intron on their tRNA genes? What are roles of the introns? So far, there are no clear answers to these questions. However, there are several examples that indicate some specific effects of tRNA introns on wide variety of aspects in the life of tRNAs and in the life of archaebacteria and eukaryotes.

First, involvement of tRNA introns as recognition motifs for tRNA modification enzymes has been known in eukaryotes (Grosjean et al., 1997). Mainly from in vitro analyses, it was found that certain modifications in the anticodon loop are strictly applied on intron-containing pre-tRNAs. One famous example is that pseudouridylation of the 1st and $3 \mathrm{rd} U$ of the anticodon
(U34 and U36) of tRNA-Ile $\mathrm{UAU}$ in S. cerevisiae (SzweykowskaKulinska et al., 1994; Simos et al., 1996; Motorin et al., 1998). tRNA-Ile UAU needs to distinguish the AUA codon for Ile from AUG for Met. Conversion of UAU into $\Psi A \Psi$ is thought to enhance selectability to A against $G$ at the wobble position. This pseudouridylation is applied only to intron-containing pretRNA-Ile UAU by pseudouridine synthase Pus1 in vitro (Figure 5A, upper) (Simos et al., 1996; Motorin et al., 1998). In. S. cerevisiae, Pus1 localizes in the nucleus, and the splicing machinery does in the cytoplasm. Thus, the order of these processing events is guaranteed by the difference in intracellular localization (Figure 5A, lower). Interestingly, Pus1 also pseudouridylates at positions 25 and 67 of both spliced and unspliced forms of tRNA-Ile UAU. A similar example of intron-dependent modification is $2^{\prime}$-Omethylation of C34 in tRNA-Leu CAA by Trm4 (Grosjean et al., 1997). Both yeast and human Trm4 methyltransferases require

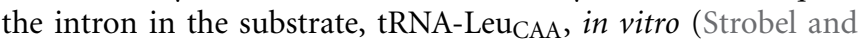
Abelson, 1986; Brzezicha et al., 2006). The intron is also used to avoid premature modification during the series of modification reactions. $\mathrm{tRNA}-\mathrm{Ph}_{\mathrm{GAA}}$, derived from intron-containing genes, has an unusual nucleotide wybutosine $(\mathrm{yW})$ at position 37 (Blobstein et al., 1975). The formation of yW starts with methylation of G37 by Trm5 in S. cerevisiae. Trm5 only recognizes the sliced but not intron-containing form of tRNA-Phe $\mathrm{GAA}_{\mathrm{GA}}$ (Figure 5B, upper) (Noma et al., 2006). Again, the spliced form

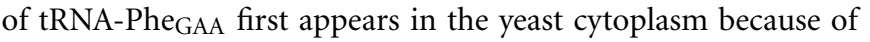
the cytoplasmic localization of the splicing machinery. However, the spliced intermediate must be re-imported into the nucleus for this methylation since Trm5 localizes in the nucleus (Ohira and Suzuki, 2011). It has been shown that various tRNA species constantly shuttle between the cytoplasm and the nucleus, and the import system can deliver the spliced intermediate to the nucleus (Shaheen and Hopper, 2005; Takano et al., 2005; Shaheen et al., 2007; see also review, Hopper, 2013). After methylation by $\operatorname{Trm} 5$, tRNA-Phe ${ }_{\mathrm{GAA}}$ with $\mathrm{m}^{1} \mathrm{G} 37$ is transported back to the cytoplasm to receive a series of chemical reactions to build $\mathrm{yW}$ at position 37 (Figure 5B, lower) (Ohira and Suzuki, 2011). In this case, the tRNA intron acts as a determinant of timing of modification.

In archaea, there is a unique example in which tRNA intron itself encodes a functional unit for modification of the body of the tRNA. In archaeal tRNA-Trp CCA precursor, a box C/D small RNA is nested in the intron, and this intronic part of pre-tRNATrp CCA or the excised intron is used to select nucleotides C34 and U39 for 2'-O-methylation in trans (Figure 5C) (Omer et al., 2000; Clouet d'Orval et al., 2001; Singh et al., 2004). Although these modifications in eukaryotes and archaea seem to be the driving force to maintain the introns in tRNA genes, the fact that Pus1 and $\operatorname{Trm} 4$ are dispensable for viability of $S$. cerevisiae is against this assumption (Simos et al., 1996; Motorin and Grosjean, 1999). It was also demonstrated that the intron of tRNA-TrpCCA can be removed from the genome of Haloferax volcanii, suggesting that modification assisted by the intronic sequence itself does not cause strong selective pressure for intron maintenance (Joardar et al., 2008). Thus, no essential modifications only applied to intron-containing pre-tRNAs have been identified in eukaryotes and archaea so far. 


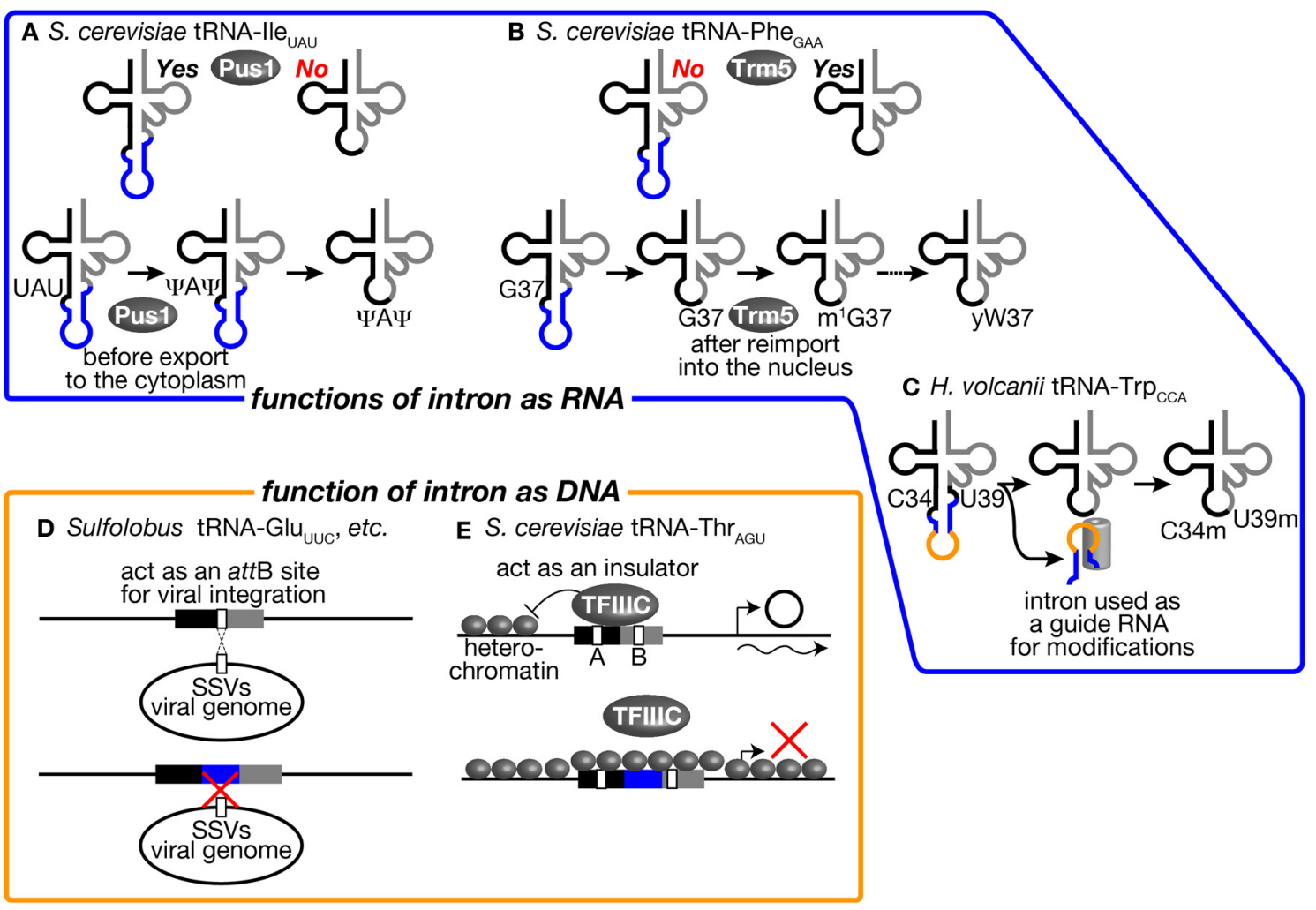

FIGURE 5 | tRNA introns affect various biological activities as RNA and DNA units. Several examples where tRNA introns affect various biological activities as RNA units (upper) and as DNA units (lower) are illustrated. (A) The intron of tRNA-lle UAU in $S$. cerevisiae is an essential recognition motif for Pus1. Thus, pseudouridylation of U34 and U36 in the anticodon by Pus1 is only applied to the intron-containing pre-tRNA. Pre-tRNA-IleuAU pseudouridylated by Pus1 in the nucleus is subjected to cytoplasmic splicing after export from the nucleus in the yeast. (B) Yeast Trm5, a nuclear methyltransferase catalyzing the initial step of $y W$ formation, only recognizes

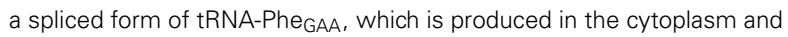
re-imported into the nucleus. Thus, yW formation starts at a late stage of
tRNA-Phe ${ }_{\text {GAA }}$ maturation. (C) The intron of tRNA-Trp ${ }_{C C A}$ in $H$. volcanii is used as a guide RNA to select two nucleotides, C34 and U39, of the same tRNA for 2'-O-methylation. (D) Sulfolobus SSVs use a part of tRNAs as an attB site for its integration into the host genome. Some Sulfolobus species harbor an intron in such tRNA genes to disrupt attB sequences. This may be a bacterial strategy to avoid viral infection. (E) tRNA-Thr AGU near the HMR-E locus, which is in a heterochromatic region, acts as an insulator and prevents expansion of the heterochromatic region over the tRNA gene by recruiting TFIIIC properly in S. cerevisiae. The intron-containing tRNA-Leu CAA gene cannot replace tRNA-Thr ${ }_{A G U}$ while the intronless version of the same tRNA can. See the text for details.

\section{POSSIBLE FUNCTIONS OF INTRON IN TRNA GENES ON THE CHROMOSOME}

The intron may affect functions or abilities of tRNA genes on chromosomes. Although the primary function of tRNA genes is the source of genetic information to produce tRNAs, their well-structured and conserved sequences are utilized as targets of integration of viral genomes and other mobile genetic elements. Randau and Söll proposed that intron insertion will prevent tRNA genes from viral genome integration (Randau and Söll, 2008). Indeed, many archaeal viruses have been isolated from extreme environments, which tRNA-intron-rich archaea also prefer (Rice et al., 2001; Prangishvili, 2013). In well-studied cases in archaea, such viruses chose tRNA genes as integration sites. For example, Sulfolobus spindle-shaped viruses (SSVs) belonging to the Fuselloviridae family use either tRNA-Leu ${ }_{\mathrm{GAG}}$, tRNA-Asp $\mathrm{GUC}$, tRNA-GluUUC, or tRNA-Glu $\mathrm{CUC}_{\mathrm{U}}$ as their attB sites, and they integrate their genome into the anticodon loop and $\mathrm{T} \Psi \mathrm{C}$ arm of these tRNA genes (Wiedenheft et al., 2004). By possessing an intron at or near the canonical position, or dividing tRNA genes into halves, such tRNA genes may escape from integration of these viruses (Figure 5D). However, there are other tRNA genes can be used as att B sites for these viruses, so that avoidance of viral infection may not be the sole reason to gain and/or maintain tRNA introns on archaeal genomes.

In eukaryotes, promoter elements are embedded in the coding region of tRNA genes, namely the A box and B box (Figure 5E) (Galli et al., 1981; Geiduschek and Kassavetis, 2001). These elements must be recognized by general transcription factor complexes in order for RNA polymerase III, especially TFIIIC, to initiate efficient transcription. Since the distance between the A and $\mathrm{B}$ boxes is altered by insertion of the intron, introns may affect recognition of the promoter elements by TFIIIC. Indeed, some early reports demonstrated that intron removal from reporter tRNA genes affects expression levels of some tRNAs in Xenopus oocytes in vivo and in yeast extracts in vitro, supporting the above assertion (Ciliberto et al., 1982; Fabrizio et al., 1987). On the other hand, other reports argue that yeast TFIIIC can bind to the tRNA promoter elements with various distance through its 
flexible linker between two recognition domains (Schultz et al., 1989; Camier et al., 1990). Recent genome-wide study of TFIII occupancy using ChIP/Seq analyses also revealed that rather even occupancy of Tfcl (TFIIIC subunit) and Brfl (TFIIIB subunit) on various tRNA genes (Nagarajavel et al., 2013). Therefore, alteration of distance between the $\mathrm{A}$ and $\mathrm{B}$ boxes by intron insertion per se may cause only minor effects on transcription of tRNA genes in general.

On the other hand, there is one example to indicate the effect of intron insertion on TFIIIC recognition of the tRNA promoter elements. It was reported that tRNA genes act as insulators or nucleosome phasing barriers (Donze et al., 1999). For this unique activity, the promoter elements of the tRNA genes must be properly occupied by TFIIIC (Simms et al., 2008). A tRNA-Thr AGU gene, which does not have an intron, next to the yeast HMR-E locus acts as an insulator to block propagation of heterochromatin over this gene. On the other hand, a tRNA-Leu ${ }_{C A A}$ gene, which has a 19 nt-long intron, cannot act as an insulator, and removal of the intron brings insulator activity to the tRNA gene (Figure 5E) (Donze and Kamakaka, 2001). Therefore, possession of the intron can affect the additional function of tRNA genes related to genome organization.

\section{DIRECT EXAMINATION OF INTRON REQUIREMENT}

Essentiality of keeping introns in tRNA genes for organisms can be directly assessed by constructing strains without tRNA introns. As mentioned above, in archaea, one report demonstrated that the intron in the tRNA-Trp $C$ CA gene is dispensable for viability of $\mathrm{H}$. volcanii in spite of its critical function in $2^{\prime}$-O-methylation of the tRNA (Joardar et al., 2008). By expanding similar analyses in certain archaea, it may be tested whether every tRNA gene harboring an intron(s) on an archaeal genome needs to possess the intron(s). On the other hand, the situation is not so simple in eukaryotes. As mentioned previously, most of isodecoder tRNAs are encoded by degenerated genes with the same or very similar sequences in eukaryotes. For example, even simple eukaryotes, such as yeasts, has more than 5 degenerated genes for each isodecoder tRNA on average. In S. cerevisiae, numbers of degenerated genes encoding intron-containing isodecoders varies from one for tRNA-Ser ${ }_{C G A}$ to 10 for tRNA-Leu ${ }_{C A A}$, tRNA-Phe ${ }_{G A A}$, and tRNA-ProugG (Lowe and Chan, 2011). Thus, only one isodecoder, tRNA-Ser ${ }_{\text {CGA }}$, was examined for dispensability of its intron in 1980s despite versatility of the yeast in chromosomal modification through homologous recombination (Ho and Abelson, 1988). Indeed, it was found that the intron in the tRNA-Ser ${ }_{\text {CGA }}$ gene can be removed from the yeast chromosome without any apparent growth defects. However, the sequence of tRNA-Ser CGA is quite similar to that of tRNA-Ser UGA $_{\text {; }}$ only three nucleotides are different between the two. Overproduction of tRNA-SerUGA can suppress lethality of deletion of the tRNA-Ser CGA $_{\text {gene, and }}$ this suppression requires $\mathrm{ncm}^{5} \mathrm{U}$ modification at U34 of tRNASer ${ }_{\text {UGA }}$ to expand its recognition repertoire at the wobble position (Johansson and Byström, 2004; Johansson et al., 2008). These facts suggest functional redundancy between tRNA-Ser CGA $_{\text {and }}$ $\mathrm{ncm}^{5} \mathrm{U}$-modified tRNA-Ser ${ }_{\mathrm{UGA}}$ and that effects of intron removal from the tRNA-Ser ${ }_{\text {CGA }}$ gene may be masked by this redundancy. A stricter test was done recently with tRNA-Trp CCA $_{\text {, which is }}$ the only isodecoder to decode a single UGG codon for Trp and encoded by six genes with the same sequences by our group (Mori et al., 2011). Complete intron removal from all the tRNA-Trp CCA genes conducted by repetitive replacement of the chromosomal tRNA genes with an intronless allele caused minimal effects on yeast growth under various conditions. In co-culture experiments with the wild-type strain up to 50 generations, the intronless strain even showed slight advantage over the wild type in growth. Furthermore, intron removal neither affects the amount and aminoacylation level of tRNA-Trp ${ }_{C C A}$, nor the protein synthesis rate while minor changes in protein composition were detected in 2D-PAGE analysis (Mori et al., 2011). Because there exists no other tRNA to decode Trp codons on the yeast genome, the above results indicate that the intron of tRNA-TrpCCA is dispensable for viability of $S$. cerevisiae. Therefore, not strict but rather subtle effects to have introns in genes of certain isodecoder tRNAs may be advantageous for organisms during evolutional time scale under the natural conditions. Or, intron insertion to and intron loss from tRNA genes are rather neutral for organisms in evolution.

\section{APPEARANCE OF INTRON-CONTAINING tRNA GENES AND ORIGIN OF INTRONS

ARCHAEBACTERIAL INTRON: ESTABLISHMENT OF ARCHETYPAL
INTRON-CONTAINING tRNA GENES AND MODERN
INTRON-CONTAINING GENES

There is a big debate on the origin of tRNA introns. One group argues for the "intron-first" scenario: all the primordial tRNA genes had an intervening sequence to be removed on the anticodon loop or consisted of a set of two halves, and then a large part of such introns have lost from the tRNA genes or the two halves have been joined on the genome during evolution (Di Giulio, 1992, 2006). The other argues for the intron-late scenario that introns were inserted after primordial tRNA genes had been established (Cavalier-Smith, 1991). From the "simpleto-complex" view, the hypothesis that tRNA is derived from a tandem duplication of a short stem-loop or ligation of two fragments may be reasonable. Indeed, existence of split tRNAs, especially those create multiple tRNAs by combination of $5^{\prime}$ - and $3^{\prime}$-halves, fits to this idea (Di Giulio, 2006). Phylogenetic analysis of archaeal tRNA genes also suggests that $5^{\prime}$ - and $3^{\prime}$-halves of tRNA genes even without introns have evolved through different evolutional trails (Fujishima et al., 2008). One and critical problem of this hypothesis is that functional units of a tRNA molecule, a decoding unit and an amino acid-accepting unit, do not correspond to these possible ancestral stem loops (Figure 1).

On the other hand, comparison of closely related species supports the idea that some "modern" introns have been inserted into tRNA genes afterwards. Many tRNA genes encoding different isodecoders in Thermoproteales genomes possess introns with very similar sequences at canonical and non-canonical positions despite the fact that the tRNA bodies are mapped at different phylogenetic positions (Fujishima et al., 2010). This finding suggests that large-scale intron transposition occurred in this order of archaea after the species had been established. Although the mechanism of intron transposition is still unknown, this is allowed because the BHB motif is required at exon-intron 
junctions and may be able to specify possible transposition targets on the chromosome. Thus, this type of intron gain by archaeal tRNA genes is supposed to proceed in the DNA level.

\section{EUKARYOTIC INTRON: POSSIBILITY OF "RECENT" GAIN OF tRNA INTRON}

Eukaryotes are thought to have evolved from an ancestral prokaryote more closely related to archaebacteria than eubacteria. So that, most of modern eukaryotic species might have lost archetypal intron-containing tRNA genes, which may be found in some of the archaeal genomes. Spectra of tRNA genes harboring an intron in eukaryotic genomes are not correlated with evolutional trails. Indeed, certain eukaryotic species possess intron-containing genes for a certain isodecoder tRNA while other species in the same clade do not. For example, the yeast Lachancea thermotolerans in Saccharomycetaceae has 3 introncontaining tRNA-Ala ${ }_{U G C}$ genes and 3 intron-containing tRNALeu $_{\text {CAG }}$ genes while other Saccharomycetaceae yeasts have only intron-less genes for these isodecoders (Figure 6A). From the sequencing analysis, the intron-containing tRNA-Leu $\mathrm{CAG}_{\text {genes }}$ seem to have emerged through codon switching by U34C mutation from tRNA-Leu $\mathrm{UAG}_{\mathrm{G}}$, which is mostly encoded by introncontaining genes in the Saccharomycetaceae yeasts. Thus, unique appearance of an intron on genes for a certain isodecoder tRNA does not necessarily mean intron gain of the tRNA genes during evolution. On the other hand, there is no tRNA paralogs encoded by intron-containing genes for tRNA-Ala $\mathrm{UGC}_{\mathrm{G}}$ in the
Saccharomycetaceae yeasts. Mature parts of this isodecoder from L. thermotolerans are highly homologous to those of the same isodecoder from other related yeasts. Thus, tRNA-Ala ${ }_{U G C}$ genes in L. thermotolerans probably acquired their intron during evolution. Another unique piece of evidence for gain of a modern intron by tRNA genes is tRNA-GlyUCC in Kluyveromyces lactis. In Saccharomycetaceae, only K. lactis has two tRNA-GlyUCC genes with a eukaryotic intron. Surprisingly, the sequence of mature tRNA-GlyUCC from K. lactis is less homologous to those of the same isodecoder from other yeasts, including those from the most related genera such as Lachancea and Eremothecium (Figure 6B), but more homologous to tRNA-GluUUC from a eubacterium, Lactobacillus plantarum, where no protein-spliced intron exists in tRNA genes (Figure 6C). These situations strongly suggest that a bacterial tRNA-GluUUC gene was horizontally transferred to the genome of $\mathrm{K}$. lactis or its close ancestor and was converted into tRNA-GlyUCC by U35C mutation. Then, the tRNA-GlyUCC gene seems to have acquired an intron. Thus, some, if not all, of introns in eukaryotic tRNA genes are suggested to have modern origins. There are many opposite cases, in which only one species lacks the intron of a certain isodecoder tRNA while the same isodecoder of other related species is encoded by intron-containing genes (see tRNA-Phe $_{\text {GAA }}$ in Figure 6A), suggesting intron-loss from tRNA genes during evolution.

Although it is easy to postulate ways of intron-loss from tRNA genes during evolution, how can a eukaryotic tRNA gene gain such a modern intron at the canonical position? Not like the
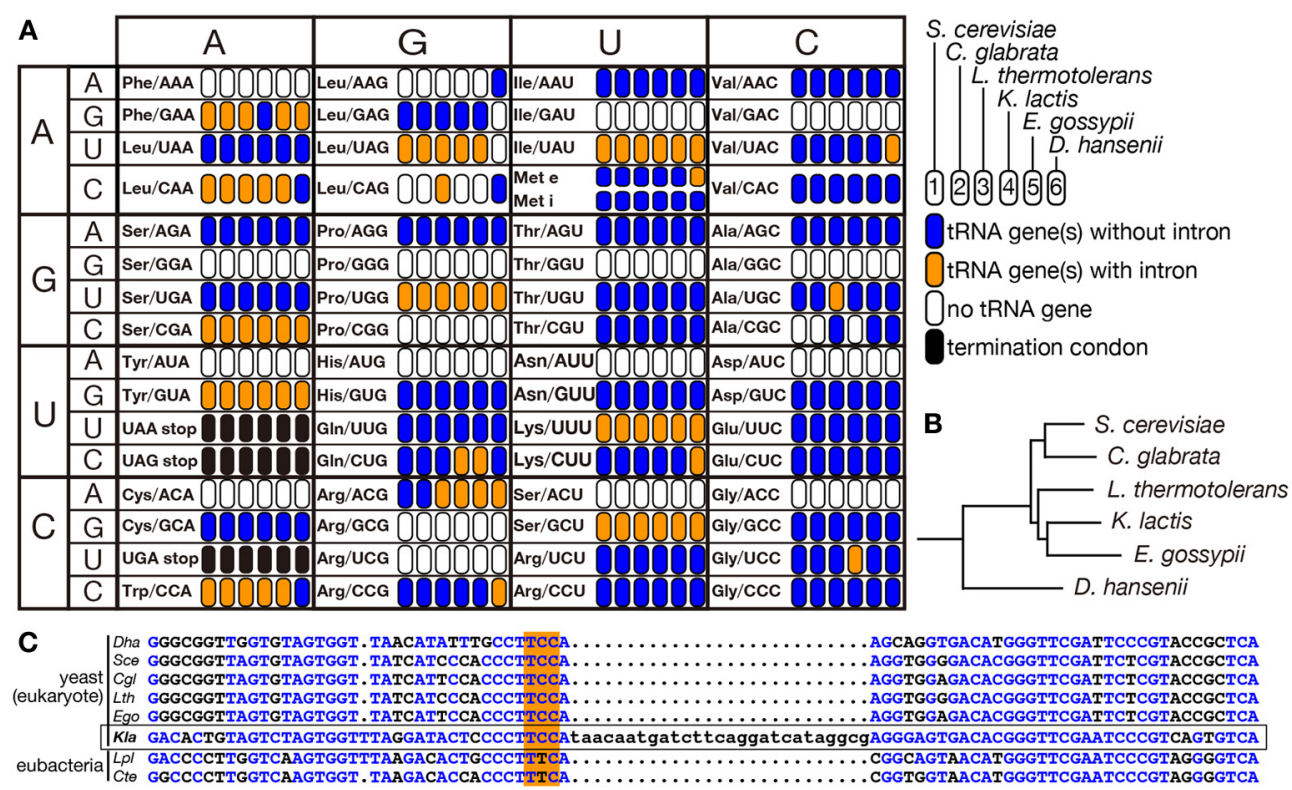

FIGURE 6 | Distribution of intron-containing tRNA genes in yeast genomes. Distribution of intron-containing genes in 6 representative yeast genomes (Saccharomyces cerevisiae, Candida glabrata, Lachancea thermotolerans, Kluyveromyces lactis, Eremothecium gossypii, and Debaryomyces hansenii) is summarized in the anti-codon table (A). As illustrated in the right, existence of intron-containing (orange) or intronless (blue) tRNA genes for each anticodon position is color-coded. Anticodon positions to which no tRNA genes are assigned on the genome or those correspond to termination codons are shown in white and black, respectively.
The phylogenetic tree of these yeasts shown in (B) was drawn according to Génolevures Consortium (2009). Among these yeast, D. hansenii does not belong to Saccharomycetaceae and is used as an outgroup. (C) Sequence comparison of tRNA-Glyucc from D. hansenii (Dha), S. cerevisiae (Sce), C. glabrata (Cgl), L. thermotolerans (Lth), E. gossypii (Ego), and K. lactis (Kla), and tRNA-Gluuuc from Lactobacillus plantarum ( $L p /$ ) and Clostridium tetanus (Cte). Nucleotides identical to those of K. lactis tRNA-Glyucc (marked with a frame) are shown in blue, and anticodons are highlighted with orange shadow. 
case of archaea, sequences of exon-intron junctions in eukaryotic pre-tRNAs do not show clear structural characteristics as mentioned above. Therefore, it is difficult to imagine mechanisms by which a DNA fragment corresponding to a tRNA intron is transposed to another position on a chromosome. Another possibility is that intron is inserted into a tRNA gene via a reversetranscribed intermediate. It is to be noted that the anticodon loop, into which eukaryotic tRNA introns are mostly inserted, is often the target of tRNA cleavage enzymes. To recognize a codon on mRNAs, the anticodon loop must be accessible to macromolecules while the $\mathrm{D}$ - and $\mathrm{T} \Psi \mathrm{C}$-loops interact with each other via base-pairing to form a tight structure. Thus, the anticodon loop is an Achilles' tendon for the tRNA to receive undesired cleavages. Well-known examples are so-called ribotoxins, such as colicin E5, and PrrC endonucleases produced by Escherichia coli, which cleave the anticodon of certain tRNAs to kill surrounding competitor bacteria and to kill itself when infected by a deadly pathogen, bacteriophage, respectively (Kaufmann, 2000). Similar anticodon nucleases are also found in eukaryotes. $\gamma$-Subunit of zymocin, produced by $K$. lactis, enters $S$. cerevisiae cells and cleaves tRNA-GluUUC if U34 of the anticodon is modified to $\mathrm{mcm}^{5} \mathrm{~s}^{2} \mathrm{U}$ (Lu et al., 2005). Eukaryotic cells also have tRNA cleavage enzymes whose targets are tRNAs in their own cells, such as Rnyl in yeast and angiogenin in mammals (Thompson and Parker, 2009; Yamasaki et al., 2009). tRNA cleavage activities of these endonucleases are regulated by cellular stresses, and the resulting tRNA fragments are used to suppress translation (Ivanov et al., 2011; Luhtala and Parker, 2012). Interestingly, the cleavage catalyzed by zymocin cannot be healed by tRNA ligase of $S$. cerevisiae, while heterologous expression of $A$. thaliana tRNA ligase can rescue $S$. cerevisiae from the deleterious effect of zymocin (Nandakumar et al., 2008). Probably, cleavage of the anticodon loop by these endonucleases is carried out so as to escape emerged RNA termini from endogenous tRNA ligase. Thus, the termini may provide initiation sites from which RNAdependent RNA polymerase extends the $5^{\prime}$-tRNA halves with unidentified templates, and then eventually its $3^{\prime}$-terminus may be ligated with the $5^{\prime}$-terminus of the $3^{\prime}$-half by tRNA ligase if these ends are recognized by healing-sealing activity of tRNA ligase (Schwer et al., 2004; Nandakumar et al., 2008). Even though such cleavage, elongation and healing might occur in the cytoplasm, the resulting tRNA derivatives might be re-imported into the nucleus using tRNA import machinery (Shaheen and Hopper, 2005; Takano et al., 2005). Thus, the tRNA derivatives can be subjected to reverse transcription and integration into the genome in the nucleus. Or, if the cleavage occurs in the nucleus, reverse transcriptase may directly elongate the $5^{\prime}$ fragment.

Both loss and gain of tRNA introns seem to have occurred during various stages of eukaryotic evolution. In addition to such events, eukaryotic genomes require another layer of gene arrangements to settle their tRNA gene repertoires. All the genes encoding a certain isodecoder tRNA on a eukaryotic genome tend to have an intron or they do not at all. Even in the cases that an isodecoder tRNA is encoded by a mixture of intron-containing and intronless genes, those intron-containing and intron-less genes are supposed to have different origins. For example, human tRNA$\mathrm{Leu}_{\mathrm{CAA}}$ is encoded by total seven genes; one intron-containing gene on Chr I, four intron-containing genes on Chr VI, one intron-less gene on Chr I, and one intron-less gene on Chr XI. Sequence comparison revealed that the intron-less gene on Chr I is more related to tRNA-Met in dog and mouse than the human intron-containing tRNA-Leu $\mathrm{CAA}_{\mathrm{A}}$ genes while that on Chr XI is more related to tRNA-Leu $\mathrm{UAG}_{\text {in }}$ human and zebrafish. Therefore, sequences of tRNA genes with the same origin are supposed to be equalized including their intronic part. This is also confirmed among species. If sequences of tRNA-Trp CCA $_{\text {genes are compared }}$ among fungal genomes, those from the same organism are clustered (Mori et al., 2011). Intergenic conversion between highly homologous tRNA genes for an isodecoder may contribute to this sequence equalization. Indeed, intergenic spreading of mutations among tRNA genes of the same isodecoder have been known for years as intergenic gene conversion hot spots (Amstutz et al., 1985; Heyer et al., 1986). Although tRNA genes are scattered around the whole yeast chromosomes, they are closely located around the nucleolus in S. cerevisiae, and near centromeres in Schizosaccharomyces pombe, which has only three chromosomes, and this intra-nuclear localization is driven by interaction between TFIIIC and condensin (Thompson et al., 2003; Haeusler et al., 2008; Iwasaki et al., 2010). Such spatial positioning of tRNA genes in the nucleus is supposed to help efficient equalization of tRNA sequences through intergenic gene conversion. We still do not know what determines balance between domination of intron-containing genes and that of intron-less genes. As described before, there seems to be no essential difference in function of tRNA molecules derived from intron-containing and intron-less genes. It might be possible that domination of introncontaining or intron-less tRNA genes for an isodecoder tRNA just comes from stochastic change between the two states during the evolution: if the one of the two types occupies all the tRNA loci, no change becomes possible until a new and very rare event of intron-loss or intron-gain occurs.

Here, I have gone through recent progresses related to tRNA introns found in both archaea and eukaryotes. The life of a tRNA molecule transcribed from intron-containing genes has been studied for decades from various points of views, and has provided various interesting findings in bioinformatics, in molecular biology, in cell biology, and even in human pathology. However, accumulating information from the experimental and computational analyses has brought us more questions to be solved, especially those related to eukaryotic tRNA introns and their splicing. Still, we do not understand completely how eukaryotic splicing endonuclease decodes hidden motifs of splice sites in eukaryotic pre-tRNAs. What kinds of substrates other than pre-tRNAs does splicing machinery process in archaea and eukaryotes? Why can tRNA introns be spliced in different intracellular compartments among eukaryotes? Are there any other physiological roles of tRNA introns in the life of tRNA or those as genetical elements on the chromosomes? What are real selective pressures to keep introns in tRNA genes if existing? Most importantly, what are origins of modern tRNA introns, and how have they appeared and disappeared in archaeal and eukaryotic genomes during evolution? Some of the questions may not be able to be answered easily, but our quest of the life of tRNAs to seek the answers is going on. 


\section{ACKNOWLEDGMENTS}

This work was supported by Grant-in-aid for Scientific Research from the Ministry of Education, Culture, Sports, Science, and Technology of Japan, and by a special grant from University of Hyogo.

\section{REFERENCES}

Akama, K., Junker, V., and Beier, H. (2000). Identification of two catalytic subunits of tRNA splicing endonuclease from Arabidopsis thaliana. Gene 257, 177-185. doi: 10.1016/S0378-1119(00)00408-X

Ameres, S. L., and Zamore, P. D. (2013). Diversifying microRNA sequence and function. Nat. Rev. Mol. Cell Biol. 14, 475-488. doi: 10.1038/nrm3611

Amstutz, H., Munz, P., Heyer, W.-D., Leupold, U., and Kohli, J. (1985). Concerted evolution of tRNA genes: intergenic conversion among three unlinked serine tRNA genes in S. pmbe. Cell 40, 879-886. doi: 10.1016/0092-8674(85) 90347-2

Auxilien, S., El Khadali, F., Rasmussen, A., Douthwaite, S., and Grosjean, H. (2007). Archease from Pyrococcus abyssi improves substrate specificity and solubility of a tRNA $\mathrm{m}^{5} \mathrm{C}$ methyltransferase. J. Biol. Chem. 282, 18711-18721. doi: 10.1074/jbc.M607459200

Blobstein, S. H., Gebert, R., Grunberger, D., Nakanishi, K., and Weinstein, I. B. (1975). Structure of the fluorescent nucleoside of yeast phenylalanine transfer ribonucleic acid. Arch. Biochem. Biophys. 167, 668-673. doi: 10.1016/00039861(75)90510-X

Brzezicha, B., Schmidt, M., Makalowska, I., Jarmolowski, A., Pienkowska, J., and Szweykowska-Kulinska, Z. (2006). Identification of human tRNA:m ${ }^{5} \mathrm{C}$ methyltransferase catalysing intron-dependent $\mathrm{m}^{5} \mathrm{C}$ formation in the first position of the anticodon of the pre-tRNA ${ }_{(\mathrm{CAA})}^{\mathrm{Leu}}$. Nucleic Acids Res. 34, 6034-6043. doi: $10.1093 / \mathrm{nar} / \mathrm{gkl} 765$

Budde, B. S., Namavar, Y., Barth, P. G., Poll-The, B. T., Nurnberg, G., Becker, C., et al. (2008). tRNA splicing endonuclease mutations cause pontocerebellar hypoplasia. Nat. Genet. 40, 1113-1118. doi: 10.1038/ng.204

Calfon, M., Zeng, H., Urano, F., Till, J. H., Hubbard, S. R., Harding, H. P., et al. (2002). IRE1 couples endoplasmic reticulum load to secretory capacity by processing the XBP-1 mRNA. Nature 415, 92-96. doi: 10.1038/415092a

Calvin, K., and Li, H. (2008). RNA-splicing endonuclease structure and function. Cell. Mol. Life Sci. 65, 1176-1185. doi: 10.1007/s00018-008-7393-y

Camier, S., Baker, R. E., and Sentenac, A. (1990). On the flexible interaction of yeast factor tau with the bipartite promoter of tRNA genes. Nucleic Acids Res. 18, 4571-4578. doi: 10.1093/nar/18.15.4571

Cavalier-Smith, T. (1991). Intron phylogeny: a new hypothesis. Trends Genet. 7, 145-148. doi: 10.1016/0168-9525(91)90102-V

Chakravarty, A. K., Subbotin, R., Chait, B. T., and Shuman, S. (2012). RNA ligase RtcB splices $3^{\prime}$-phosphate and $5^{\prime}-\mathrm{OH}$ ends via covalent RtcB-(histidinyl)-GMP and polynucleotide- $\left(3^{\prime}\right) \mathrm{pp}\left(5^{\prime}\right) \mathrm{G}$ intermediates. Proc. Natl. Acad. Sci. U.S.A. 109, 6072-6077. doi: 10.1073/pnas.1201207109

Chan, P. P., Cozen, A. E., and Lowe, T. M. (2011). Discovery of permuted and recently split transfer RNAs in Archaea. Genome Biol. 12:R38. doi: 10.1186/gb2011-12-4-r38

Ciliberto, G., Traboni, C., and Cortese, R. (1982). Relationship between the two components of the split promoter of eukaryotic tRNA genes. Proc. Natl. Acad. Sci. U.S.A. 79, 1921-1925. doi: 10.1073/pnas.79.6.1921

Clouet d'Orval, B., Bortolin, M. L., Gaspin, C., and Bachellerie, J. P. (2001). Box C/D RNA guides for the ribose methylation of archaeal tRNAs. The tRNATrp intron guides the formation of two ribose-methylated nucleosides in the mature tRNATrp. Nucleic Acids Res. 29, 4518-4529. doi: 10.1093/nar/29.22.4518

Cognat, V., Pawlak, G., Duchene, A. M., Daujat, M., Gigant, A., Salinas, T., et al. (2013). PlantRNA, a database for tRNAs of photosynthetic eukaryotes. Nucleic Acids Res. 41, D273-D279. doi: 10.1093/nar/gks935

Culver, G. M., McCraith, S. M., Consaul, S. A., Stanford, D. R., and Phizicky, E. M. (1997). A $2^{\prime}$-phosphotransferase implicated in tRNA splicing is essential in Saccharomyces cerevisiae. J. Biol. Chem. 272, 13203-13210. doi: 10.1074/jbc.272.20.13203

De Robertis, E. M., Black, P., and Nishikura, K. (1981). Intranuclear location of the tRNA splicing enzymes. Cell 23, 89-93. doi: 10.1016/0092-8674(81)90273-7

Desai, K. K., Cheng, C. L., Bingman, C. A., Phillips, G. N. Jr., and Raines, R. T. (2014). A tRNA splicing operon: archease endows RtcB with dual
GTP/ATP cofactor specificity and accelerates RNA ligation. Nucleic Acids Res. 42, 3931-3942. doi: 10.1093/nar/gkt1375

de Vries, H., Ruegsegger, U., Hubner, W., Friedlein, A., Langen, H., and Keller, W. (2000). Human pre-mRNA cleavage factor II(m) contains homologs of yeast proteins and bridges two other cleavage factors. EMBO J. 19, 5895-5904. doi: 10.1093/emboj/19.21.5895

Dhungel, N., and Hopper, A. K. (2012). Beyond tRNA cleavage: novel essential function for yeast tRNA splicing endonuclease unrelated to tRNA processing. Genes Dev. 26, 503-514. doi: 10.1101/gad.183004.111

Di Giulio, M. (1992). On the origin of the transfer RNA molecule. J. Theor. Biol. 159, 199-214. doi: 10.1016/S0022-5193(05)80702-7

Di Giulio, M. (2006). The non-monophyletic origin of the tRNA molecule and the origin of genes only after the evolutionary stage of the last universal common ancestor (LUCA). J. Theor. Biol. 240, 343-352. doi: 10.1016/j.jtbi.2005.09.023

Di Segni, G., Borghese, L., Sebastiani, S., and Tocchini-Valentini, G. P. (2005). A pre-tRNA carrying intron features typical of Archaea is spliced in yeast. RNA 11, 70-76. doi: 10.1261/rna.7138805

Donze, D., Adams, C. R., Rine, J., and Kamakaka, R. T. (1999). The boundaries of the silenced HMR domain in Saccharomyces cerevisiae. Genes Dev. 13, 698-708. doi: 10.1101/gad.13.6.698

Donze, D., and Kamakaka, R. T. (2001). RNA polymerase III and RNA polymerase II promoter complexes are heterochromatin barriers in Saccharomyces cerevisiae. EMBO J. 20, 520-531. doi: 10.1093/emboj/20.3.520

Edvardson, S., Shaag, A., Kolesnikova, O., Gomori, J. M., Tarassov, I., Einbinder, T., et al. (2007). Deleterious mutation in the mitochondrial arginyl-transfer RNA synthetase gene is associated with pontocerebellar hypoplasia. Am. J. Hum. Genet. 81, 857-862. doi: 10.1086/521227

Englert, M., and Beier, H. (2005). Plant tRNA ligases are multifunctional enzymes that have diverged in sequence and substrate specificity from RNA ligases of other phylogenetic origins. Nucleic Acids Res. 33, 388-399. doi: 10.1093/nar/gki174

Englert, M., Latz, A., Becker, D., Gimple, O., Beier, H., and Akama, K. (2007). Plant pre-tRNA splicing enzymes are targeted to multiple cellular compartments. Biochimie 89, 1351-1365. doi: 10.1016/j.biochi.2007.06.014

Englert, M., Sheppard, K., Aslanian, A., Yates, J. R. I., and Söll, D. (2011). Archaeal $3^{\prime}$-phosphate RNA splicing ligase characterization identifies the missing component in tRNA maturation. Proc. Natl. Acad. Sci. U.S.A. 108, 1290-1295. doi: 10.1073/pnas. 1018307108

Englert, M., Sheppard, K., Gundllapalli, S., Beier, H., and Söll, D. (2010). Branchiostoma floridae has separate healing and sealing enzymes for $5^{\prime}$ phosphate RNA ligation. Proc. Natl. Acad. Sci. U.S.A. 107, 16834-16839. doi: 10.1073/pnas.1011703107

Fabbri, S., Fruscoloni, P., Bufardeci, E., Di Nicola Negri, E., Baldi, M. I., Attardi, D. G., et al. (1998). Conservation of substrate recognition mechanisms by tRNA splicing endonucleases. Science 280, 284-286. doi: 10.1126/science.280.5361.284

Fabrizio, P., Coppo, A., Fruscoloni, P., Benedetti, P., Di Segni, G., and TocchiniValentini, G. P. (1987). Comparative mutational analysis of wild-type and stretched tRNA ${ }_{3}^{\text {Leu }}$ gene promoters. Proc. Natl. Acad. Sci. U.S.A. 84, 8763-8767. doi: $10.1073 /$ pnas.84.24.8763

Filipowicz, W., and Shatkin, A. J. (1983). Origin of splice junction phosphate in tRNAs processed by HeLa cell extract. Cell 32, 547-557. doi: 10.1016/00928674(83)90474-9

Fujishima, K., Sugahara, J., Kikuta, K., Hirano, R., Sato, A., Tomita, M., et al. (2009). Tri-split tRNA is a transfer RNA made from 3 transcripts that provides insight into the evolution of fragmented tRNAs in archaea. Proc. Natl. Acad. Sci. U.S.A. 106, 2683-2687. doi: 10.1073/pnas.0808246106

Fujishima, K., Sugahara, J., Tomita, M., and Kanai, A. (2008). Sequence evidence in the archaeal genomes that tRNAs emerged through the combination of ancestral genes as $5^{\prime}$ and $3^{\prime}$ tRNA halves. PLoS ONE 3:e1622. doi: 10.1371/journal.pone. 0001622

Fujishima, K., Sugahara, J., Tomita, M., and Kanai, A. (2010). Large-scale tRNA intron transposition in the archaeal order Thermoproteales represents a novel mechanism of intron gain. Mol. Biol. Evol. 27, 2233-2243. doi: 10.1093/mol$\mathrm{bev} / \mathrm{msq} 111$

Galli, G., Hofstetter, H., and Birnstiel, M. L. (1981). Two conserved sequence blocks within eukaryotic tRNA genes are major promoter elements. Nature 294, 626-631. doi: 10.1038/294626a0

Geiduschek, E. P., and Kassavetis, G. A. (2001). The RNA polymerase III transcription apparatus. J. Mol. Biol. 310, 1-26. doi: 10.1006/jmbi.2001.4732 
Génolevures Consortium. (2009). Comparative genomics of protoploid Saccharomycetaeae. Genome Res. 19, 1696-1709. doi: 10.1101/gr.091546.109

Greer, C. L., Söll, D., and Willis, I. (1987). Substrate recognition and identification of splice sites by the tRNA-splicing endonuclease and ligase from Saccharomyces cerevisiae. Mol. Cell. Biol. 7, 76-84.

Grosjean, H., Szweykowska-Kulinska, Z., Motorin, Y., Fasiolo, F., and Simos, G. (1997). Intron-dependent enzymatic formation of modified nucleosides in eukaryotic tRNAs: a review. Biochimie 79, 293-302. doi: 10.1016/S03009084(97)83517-1

Haeusler, R. A., Pratt-Hyatt, M., Good, P. D., Gipson, T. A., and Engelke, D. R. (2008). Clustering of yeast tRNA genes is mediated by specific association of condensin with tRNA gene transcription complexes. Genes Dev. 22, 2204-2214. doi: 10.1101/gad.1675908

Hanada, T., Weitzer, T., Mair, B., Bernreuther, C., Wainger, B. J., Ichida, J., et al. (2013). CLP1 links tRNA metabolism to progressive motor-neuron loss. Nature 495, 474-480. doi: 10.1038/nature11923

Harding, H. P., Lackey, J. G., Hsu, H. C., Zhang, Y., Deng, J., Xu, R. M., et al. (2008). An intact unfolded protein response in Trpt1 knockout mice reveals phylogenic divergence in pathways for RNA ligation. RNA 14, 225-232. doi: 10.1261/rna.859908

Haugen, P., Simon, D. M., and Bhattacharya, D. (2005). The natural history of group I introns. Trends Genet. 21, 111-119. doi: 10.1016/j.tig.2004.12.007

Heinemann, I. I., Söll, D., and Randau, L. (2010). Transfer RNA processing in archaea: unusual pathways and enzymes. FEBS Lett. 584, 303-309. doi: 10.1016/j.febslet.2009.10.067

Heyer, W.-D., Munz, P., Amstutz, H., Aebi, R., Gysler, C., Schuchert, P., et al. (1986). Inactivation of nonsense suppressor transfer RNA genes in Schizosaccharomyces pombe: intergenic conversion and hot spots of mutation. J. Mol. Biol. 188, 343-353. doi: 10.1016/0022-2836(86)90159-2

Ho, C. K., and Abelson, J. (1988). Testing for intron function in the essential Saccharomyces cerevisiae tRNA $\mathrm{UCG}_{\mathrm{UCG}}^{\mathrm{gene}}$ J. Mol. Biol. 202, 667-672. doi: 10.1016/0022-2836(88)90295-1

Hopper, A. K. (2013). Transfer RNA post-transcriptional processing, turnover, and subcellular dynamics in the yeast Saccharomyces cerevisiae. Genetics 194, 43-67. doi: 10.1534/genetics.112.147470

Ivanov, P., Emara, M. M., Villen, J., Gygi, S. P., and Anderson, P. (2011). Angiogenin-induced tRNA fragments inhibit translation initiation. Mol. Cell 43, 613-623. doi: 10.1016/j.molcel.2011.06.022

Iwasaki, O., Tanaka, A., Tanizawa, H., Grewal, S. I., and Noma, K. (2010). Centromeric localization of dispersed Pol III genes in fission yeast. Mol. Biol. Cell 21, 254-265. doi: 10.1091/mbc.E09-09-0790

Joardar, A., Gurha, P., Skariah, G., and Gupta, R. (2008). Box C/D RNA-guided 2' $\mathrm{O}$ methylations and the intron of tRNA ${ }^{\text {Trp }}$ are not essential for the viability of Haloferax volcanii. J. Bacteriol. 190, 7308-7313. doi: 10.1128/JB.00820-08

Johansson, M. J., Esberg, A., Huang, B., Bjork, G. R., and Byström, A. S. (2008). Eukaryotic wobble uridine modifications promote a functionally redundant decoding system. Mol. Cell. Biol. 28, 3301-3312. doi: 10.1128/MCB. 01542-07

Johansson, M. J. O., and Byström, A. S. (2004). The Saccharomyces cerevisiae TAN1 gene is required for $N^{4}$-acetylcytidine formation in tRNA. RNA 10, 712-719. doi: 10.1261/rna.5198204

Karaca, E., Weitzer, S., Pehlivan, D., Shiraishi, H., Gogakos, T., Hanada, T., et al. (2014). Human CLP1 mutations alter tRNA biogenesis, affecting both peripheral and central nervous system function. Cell 157, 636-650. doi: 10.1016/j.cell.2014.02.058

Kanai, Y., Dohmae, N., and Hirokawa, N. (2004). Kinesin transports RNA: isolation and characterization of an RNA-transporting granule. Neuron 43, 513-525. doi: 10.1016/j.neuron.2004.07.022

Kasher, P. R., Namavar, Y., van Tijn, P., Fluiter, K., Sizarov, A., Kamermans, M., et al. (2011). Impairment of the tRNA-splicing endonuclease subunit 54 (tsen54) gene causes neurological abnormalities and larval death in zebrafish models of pontocerebellar hypoplasia. Hum. Mol. Genet. 20, 1574-1584. doi: $10.1093 / \mathrm{hmg} / \mathrm{ddr} 034$

Kaufmann, G. (2000). Anticodon nucleases. Trends Biochem. Sci. 25, 70-74. doi: 10.1016/S0968-0004(99)01525-X

Kawach, O., Voss, C., Wolff, J., Hadfi, K., Maier, U. G., and Zauner, S. (2005). Unique tRNA introns of an enslaved algal cell. Mol. Biol. Evol. 22, 1694-1701. doi: $10.1093 / \mathrm{molbev} / \mathrm{msil} 61$
Kjems, J., and Garrett, R. A. (1988). Novel splicing mechanism for the ribosomal RNA intron in the archaebacterium Desulfurococcus mobilis. Cell 54, 693-703. doi: 10.1016/S0092-8674(88)80014-X

Kleman-Leyer, K., Armbruster, D.-W., and Daniels, C. D. (1997). Properties of $H$. volcanii tRNA intron endonuclease reveal a relationship between the archaeal and eucaryal tRNA intron processing systems. Cell 89, 839-847. doi: 10.1016/S0092-8674(00)80269-X

Lappe-Siefke, C., Goebbels, S., Gravel, M., Nicksch, E., Lee, J., Braun, P. E., et al. (2003). Disruption of Cnpl uncouples oligodendroglial functions in axonal support and myelination. Nat. Genet. 33, 366-374. doi: 10.1038/ ng1095

Laski, F. A., Fire, A. Z., RajBhandary, U. L., and Sharp, P. A. (1983). Characterization of tRNA precursor splicing in mammalian extracts. J. Biol. Chem. 258, 11974-11980.

Lee, M.-C., and Knapp, G. (1985). Transfer RNA splicing in Saccharomyces cerevisiae: secondary and tertiary structures of the substrates. J. Biol. Chem. 260, 3108-3115.

Li, H., and Abelson, J. (2000). Crystal structure of a dimeric archaeal splicing endonuclease. J. Mol. Biol. 302, 639-648. doi: 10.1006/jmbi.2000.3941

Li, H., Trotta, C. R., and Abelson, J. (1998). Crystal structure and evolution of a transfer RNA splicing enzyme. Science 280, 279-284. doi: 10.1126/science.280.5361.279

Lowe, T. M., and Eddy, S. R. (1997). tRNAscan-SE: a program for improved detection of transfer RNA genes in genomic sequence. Nucleic Acids Res. 25, 955-964. doi: $10.1093 /$ nar/25.5.0955

Lowe, T., and Chan, P. (2011). Genomic tRNA Database. Available online at: http:// lowelab.ucsc.edu/GtRNAdb/

Lu, J., Huang, B., Esberg, A., Johansson, M. J., and Byström, A. S. (2005). The Kluyveromyces lactis $\gamma$-toxin targets tRNA anticodons. RNA 11, 1648-1654. doi: 10.1261/rna.2172105

Luhtala, N., and Parker, R. (2012). Structure-function analysis of Rnyl in tRNA cleavage and growth inhibition. PLOS ONE 7:e41111. doi: 10.1371/journal.pone.0041111

Lykke-Andersen, J., and Garrett, R. A. (1997). RNA-protein interactions of an archaeal homotetrameric splicing endoribonuclease with an exceptional evolutionary history. EMBO J. 16, 6290-6300. doi: 10.1093/emboj/16.20.6290

Makarova, K. S., and Koonin, E. V. (2005). Evolutionary and functional genomics of the Archaea. Curr. Opin. Microbiol. 8, 586-594. doi: 10.1016/j.mib.2005. 08.003

Marck, C., and Grosjean, H. (2003). Identification of BHB splicing motifs in intron-containing tRNAs from 18 archaea: evolutionary implications. RNA 9, 1516-1531. doi: 10.1261/rna.5132503

Maruyama, S., Sugahara, J., Kanai, A., and Nozaki, H. (2010). Permuted tRNA genes in the nuclear and nucleomorph genomes of photosynthetic eukaryotes. Mol. Biol. Evol. 27, 1070-1076. doi: 10.1093/molbev/msp313

Mitchell, M., Xue, S., Erdman, R., Randau, L., Söll, D., and Li, H. (2009). Crystal structure and assembly of the functional Nanoarchaeum equitans tRNA splicing endonuclease. Nucleic Acids Res. 37, 5793-5802. doi: 10.1093/nar/ gkp537

Mori, S., Kajita, T., Endo, T., and Yoshihisa, T. (2011). The intron of tRNA-Trp $C C A$ is dispensable for growth and translation of Saccharomyces cerevisiae. RNA 17, 1760-1769. doi: 10.1261/rna.2851411

Mori, T., Ogasawara, C., Inada, T., Englert, M., Beier, H., Takezawa, M., et al. (2010). Dual functions of yeast tRNA ligase in the unfolded protein response: unconventional cytoplasmic splicing of HAC1 pre-mRNA is not sufficient to release translational attenuation. Mol. Biol. Cell 21, 3722-3734. doi: 10.1091/mbc.E10-08-0693

Motorin, Y., and Grosjean, H. (1999). Multisite-specific tRNA: ${ }^{5} \mathrm{C}$ methyltransferase (Trm4) in yeast Saccharomyces cerevisiae: identification of the gene and substrate specificity of the enzyme. RNA 5, 1105-1118. doi: 10.1017/S1355838299982201

Motorin, Y., Keith, G., Simon, C., Foiret, D., Simos, G., Hurt, E., et al. (1998). The yeast tRNA:pseudouridine synthase Puslp displays a multisite substrate specificity. RNA 4, 856-869. doi: 10.1017/S1355838298980396

Nagarajavel, V., Iben, J. R., Howard, B. H., Maraia, R. J., and Clark, D. J. (2013). Global 'bootprinting' reveals the elastic architecture of the yeast TFIIIBTFIIIC transcription complex in vivo. Nucleic Acids Res. 41, 8135-8143. doi: $10.1093 /$ nar/gkt611 
Namavar, Y., Barth, P. G., Kasher, P. R., van Ruissen, F., Brockmann, K., Bernert, G., et al. (2011). Clinical, neuroradiological and genetic findings in pontocerebellar hypoplasia. Brain 134, 143-56. doi: 10.1093/brain/awq287

Nandakumar, J., Schwer, B., Schaffrath, R., and Shuman, S. (2008). RNA repair: an antidote to cytotoxic eukaryal RNA damage. Mol. Cell 31, 278-286. doi: 10.1016/j.molcel.2008.05.019

Noma, A., Kirino, Y., Ikeuchi, Y., and Suzuki, T. (2006). Biosynthesis of wybutosine, a hyper-modified nucleoside in eukaryotic phenylalanine tRNA. EMBO J. 25, 2142-2154. doi: 10.1038/sj.emboj.7601105

Nykänen, A., Haley, B., and Zamore, P. D. (2001). ATP requirements and small interfering RNA structure in the RNA interference pathway. Cell 107, 309-321. doi: 10.1016/S0092-8674(01)00547-5

Ohira, T., and Suzuki, T. (2011). Retrograde nuclear import of tRNA precursors is required for modified base biogenesis in yeast. Proc. Natl. Acad. Sci. U.S.A. 108, 10502-10507. doi: 10.1073/pnas.1105645108

Omer, A. D., Lowe, T. M., Russell, A. G., Ebhardt, H., Eddy, S. R., and Dennis, P. P. (2000). Homologs of small nucleolar RNAs in archaea. Science 288, 517-522. doi: 10.1126/science.288.5465.517

Park, M. Y., Wu, G., Gonzalez-Sulser, A., Vaucheret, H., and Poethig, R. S. (2005). Nuclear processing and export of microRNAs in Arabidopsis. Proc. Natl. Acad. Sci. U.S.A. 102, 3691-3696. doi: 10.1073/pnas.0405570102

Paushkin, S. V., Patel, M., Furia, B. S., Peltz, S. W., and Trotta, C. R. (2004). Identification of a human endonuclease complex reveals a link between tRNA splicing and pre-mRNA $3^{\prime}$ end formation. Cell 117, 311-321. doi: 10.1016/S0092-8674(04)00342-3

Pérez-González, A., Pazo, A., Navajas, R., Ciordia, S., Rodriguez-Frandsen, A., and Nieto, A. (2014). hCLE/C14orf166 associates with DDX1-HSPC117-FAM98B in a novel transcription-dependent shuttling RNA-transporting complex. PLoS ONE 9:e90957. doi: 10.1371/journal.pone.0090957

Phizicky, E. M., and Hopper, A. K. (2010). tRNA biology charges to the front. Genes Dev. 24, 1832-1860. doi: 10.1101/gad.1956510

Phizicky, E. M., Schwartz, R. C., and Abelson, J. (1986). Saccharomyces cerevisiae tRNA ligase: purification of the protein and isolation of the structural gene. J. Biol. Chem. 261, 2978-2986.

Popow, J., Englert, M., Weitzer, S., Schleiffer, A., Mierzwa, B., Mechtler, K., et al. (2011). HSPC117 is the essential subunit of a human tRNA splicing ligase complex. Science 331, 760-764. doi: 10.1126/science.1197847

Popow, J., Schleiffer, A., and Martinez, J. (2012). Diversity and roles of (t)RNA ligases. Cell. Mol. Life Sci. 69, 2657-2670. doi: 10.1007/s00018-012-0944-2

Popow, P., Jurkin, J., Schleiffer, J., and Martinez, J. (2014). Analysis of orthologous groups reveals Archease and DDX1 as tRNA splicing factors. Nature 511, 104-107. doi: 10.1038/nature13284

Prangishvili, D. (2013). The wonderful world of archaeal viruses. Annu. Rev. Microbiol. 67, 565-585. doi: 10.1146/annurev-micro-092412-155633

Randau, L., Calvin, K., Hall, M., Yuan, J., Podar, M., Li, H., et al. (2005a). The heteromeric Nanoarchaeum equitans splicing endonuclease cleaves noncanonical bulge-helix-bulge motifs of joined tRNA halves. Proc. Natl. Acad. Sci. U.S.A. 102, 17934-17939. doi: 10.1073/pnas.0509197102

Randau, L., Münch, R., Hohn, M. J., Jahn, D., and Söll, D. (2005b). Nanoarchaeum equitans creates functional tRNAs from separate genes for their $5^{\prime}$ - and $3^{\prime}$ halves. Nature 433, 537-541. doi: 10.1038/nature03233

Randau, L., Pearson, M., and Söll, D. (2005c). The complete set of tRNA species in Nanoarchaeum equitans. FEBS Lett. 579, 2945-2947. doi: 10.1016/j.febslet.2005.04.051

Randau, L., and Söll, D. (2008). Transfer RNA genes in pieces. EMBO Rep. 9, 623-628. doi: 10.1038/embor.2008.101

Rauhut, R., Green, P. R., and Abelson, J. (1990). Yeast tRNA-splicing endonuclease is a heterotrimeric enzyme. J. Biol. Chem. 265, 18180-18184.

Reinhold-Hurek, B., and Shub, D. A. (1992). Self-splicing introns in tRNA genes of widely divergent bacteria. Nature $357,173-176$. doi: 10.1038/357173a0

Reyes, V. M., and Abelson, J. (1988). Substrate recognition and splice site determination in yeast tRNA splicing. Cell 55, 719-730. doi: 10.1016/00928674(88)90230-9

Rice, G., Stedman, K., Snyder, J., Wiedenheft, B., Willits, D., Brumfield, S., et al. (2001). Viruses from extreme thermal environments. Proc. Natl. Acad. Sci. U.S.A. 98, 13341-13345. doi: 10.1073/pnas. 231170198

Sawaya, R., Schwer, B., and Shuman, S. (2003). Genetic and biochemical analysis of the functional domains of yeast tRNA ligase. J. Biol. Chem. 278, 43928-43938. doi: 10.1074/jbc.M307839200
Schaffer, A. E., Eggens, V. R. C., Caglayan, A. O., Reuter, M. S., Scott, E., Coufal, N. G., et al. (2014). CLP1 founder mutation links tRNA splicing and maturation to cerebellar development and neurodegeneration. Cell 157, 651-663. doi: 10.1016/j.cell.2014.03.049

Schultz, P., Marzoukil, N., Marck, C., Ruet, A., Oudet, P., and Entenac, A. (1989). The two DNA-binding domains of yeast transcription factor $\tau$ as observed by scanning transmission electron microscopy. EMBO J. 8, 3815-3824.

Schwer, B., Sawaya, R., Ho, C. K., and Shuman, S. (2004). Portability and fidelity of RNA-repair systems. Proc. Natl. Acad. Sci. U.S.A. 101, 2788-2793. doi: 10.1073/pnas.0305859101

Shaheen, H. H., and Hopper, A. K. (2005). Retrograde movement of tRNAs from the cytoplasm to the nucleus in Saccharomyces cerevisiae. Proc. Natl. Acad. Sci. U.S.A. 102, 11290-11295. doi: 10.1073/pnas.0503836102

Shaheen, H. H., Horetsky, R. L., Kimball, S. R., Murthi, A., Jefferson, L. S., and Hopper, A. K. (2007). Retrograde nuclear accumulation of cytoplasmic tRNA in rat hepatoma cells in response to amino acid deprivation. Proc. Natl. Acad. Sci. U.S.A. 104, 8845-8850. doi: 10.1073/pnas.0700765104

Sharma, K., Fabre, E., Tekotte, H., Hurt, E. C., and Tollervey, D. (1996). Yeast nucleoporin mutants are defective in pre-tRNA splicing. Mol. Cell. Biol. 26, 294-301.

Sidrauski, C., Cox, J. S., and Walter, P. (1996). tRNA ligase is required for regulated mRNA splicing in the unfolded protein response. Cell 87, 405-413. doi: 10.1016/S0092-8674(00)81361-6

Simms, T. A., Dugas, S. L., Gremillion, J. C., Ibos, M. E., Dandurand, M. N., Toliver, T. T., et al. (2008). TFIIIC binding sites function as both heterochromatin barriers and chromatin insulators in Saccharomyces cerevisiae. Eukaryot. Cell 7, 2078-2086. doi: 10.1128/EC.00128-08

Simos, G., Tekotte, H., Grosjean, H., Segref, A., Sharma, K., Tollervey, D., et al. (1996). Nuclear pore proteins are involved in the biogenesis of functional tRNA. EMBO J. 15, 2270-2284.

Singh, S. K., Gurha, P., Tran, E. J., Maxwell, E. S., and Gupta, R. (2004). Sequential $2^{\prime}$-O-methylation of archaeal pre-tRNA ${ }^{\operatorname{Tr} p}$ nucleotides is guided by the intronencoded but trans-acting box C/D ribonucleoprotein of pre-tRNA. J. Biol. Chem. 279, 47661-47671. doi: 10.1074/jbc.M408868200

Soma, A., Onodera, A., Sugahara, J., Kanai, A., Yachie, N., Tomita, M., et al. (2007). Permuted tRNA genes expressed via a circular RNA intermediate in Cyanidioschyzon merolae. Science 318, 450-453. doi: 10.1126/science.1145718

Soma, A., Sugahara, J., Onodera, A., Yachie, N., Kanai, A., Watanabe, S., et al. (2013). Identification of highly-disrupted tRNA genes in nuclear genome of the red alga, Cyanidioschyzon merolae 10D. Sci. Rep. 3:2321. doi: 10.1038/ srep02321

Strobel, M. C., and Abelson, J. (1986). Effect of intron mutations on processing and function of Saccharomyces cerevisiae SUP53 tRNA in vitro and in vivo. Mol. Cell. Biol. 6, 2663-2673.

Sugahara, J., Fujishima, K., Morita, K., Tomita, M., and Kanai, A. (2009). Disrupted tRNA gene diversity and possible evolutionary scenarios. J. Mol. Evol. 69, 497-504. doi: 10.1007/s00239-009-9294-6

Sugahara, J., Kikuta, K., Fujishima, K., Yachie, N., Tomita, M., and Kanai, A. (2008). Comprehensive analysis of archaeal tRNA genes reveals rapid increase of tRNA introns in the order Thermoproteales. Mol. Biol. Evol. 25, 2709-2716. doi: $10.1093 / \mathrm{molbev} / \mathrm{msn} 216$

Sugahara, J., Yachie, N., Arakawa, K., and Tomita, M. (2007). In silico screening of archaeal tRNA-encoding genes having multiple introns with bulge-helix-bulge splicing motifs. RNA 13, 671-681. doi: 10.1261/rna.309507

Sugahara, J., Yachie, N., Sekine, Y., Soma, A., Matsui, M., Tomita, M., et al. (2006). SPLITS: a new program for predicting split and intron-containing tRNA genes at the genome level. In Silico Biol. 6, 411-418.

Swerdlow, H., and Guthrie, C. (1984). Structure of intron-containing tRNA precursors: analysis of solution conformation using chemical and enzymatic probes. J. Biol. Chem. 259, 5197-5207.

Szweykowska-Kulinska, Z., Senger, B., Keith, G., Fasiolo, F., and Grosjean, H. (1994). Intron-dependent formation of pseudouridines in the anticodon of Saccharomyces cerevisiae minor tRNA ${ }^{\text {Ile }}$. EMBO J. 13, 4636-4644.

Takano, A., Endo, T., and Yoshihisa, T. (2005). tRNA actively shuttles between the nucleus and cytosol in yeast. Science 309, 140-142. doi: 10.1126/science. 1113346

Tanaka, N., and Shuman, S. (2011). RtcB is the RNA ligase component of an Escherichia coli RNA repair operon. J. Biol. Chem. 286, 7727-7731. doi: 10.1074/jbc.C111.219022 
Tang, T. H., Rozhdestvensky, T. S., Clouet d'Orval, B., Bortolin, M.-L., Huber, H., Charpentier, B., et al. (2002). RNomics in Archaea reveals a further link between splicing of archaeal introns and rRNA processing. Nucleic Acids Res. 30, 921-930. doi: 10.1093/nar/30.4.921

Tanner, N. K., Hanna, M. M., and Abelson, J. (1988). Binding interactions between yeast tRNA ligase and a precursor transfer ribonucleic acid containing two photoreactive uridine analogues. Biochemistry 27, 8852-8861. doi: 10.1021/bi00424a025

Thompson, D. M., and Parker, R. (2009). The RNase Rnylp cleaves tRNAs and promotes cell death during oxidative stress in Saccharomyces cerevisiae. J. Cell Biol. 185, 43-50. doi: 10.1083/jcb.200811119

Thompson, L. D., and Daniel, C. J. (1990). Recognition of exon-intron boundaries by the Halobacterium volcanii tRNA intron endonuclease. J. Biol. Chem. 265, 18104-18111.

Thompson, M., Haeusler, R. A., Good, P. D., and Engelke, D. R. (2003). Nucleolar clustering of dispersed tRNA genes. Science 302, 1399-1401. doi: 10.1126/science. 1089814

Tocchini-Valentini, G. D., Fruscoloni, P., and Tocchini-Valentini, G. P. (2005). Coevolution of tRNA intron motifs and tRNA endonuclease architecture in Archaea. Proc. Natl. Acad. Sci. U.S.A. 102, 15418-15422. doi: 10.1073/pnas.0506750102

Trotta, C. R., Miao, F., Arn, E. A., Stevens, S. W., Ho, C. K., Rauhut, R., et al. (1997). The yeast tRNA splicing endonuclease: a tetrameric enzyme with two active site subunits homologuos to the archaeal tRNA endonucleases. Cell 89, 849-858. doi: 10.1016/S0092-8674(00)80270-6

Trotta, C. R., Paushkin, S. V., Patel, M., Li, H., and Peltz, S. W. (2006). Cleavage of pre-tRNAs by the splicing endonuclease requires a composite active site. Nature 441, 375-377. doi: 10.1038/nature04741

Wang, L. K., Schwer, B., Englert, M., Beier, H., and Shuman, S. (2006). Structurefunction analysis of the kinase-CPD domain of yeast tRNA ligase (Trl1) and requirements for complementation of tRNA splicing by a plant Trl1 homolog. Nucleic Acids Res. 34, 517-527. doi: 10.1093/nar/gkj441

Wang, L. K., and Shuman, S. (2005). Structure-function analysis of yeast tRNA ligase. RNA 11, 966-975. doi: 10.1261/rna.2170305

Weitzer, S., and Martinez, J. (2007). The human RNA kinase hClpl is active on $3^{\prime}$ transfer RNA exons and short interfering RNAs. Nature 447, 222-226. doi: 10.1038 /nature 05777

Westaway, S. K., Belford, H. G., Apostol, B. L., Abelson, J., and Greer, C. L. (1993). Novel activity of a yeast ligase deletion polypeptide: evidence for GTP-dependent tRNA splicing. J. Biol. Chem. 268, 2435-2443.

Wiedenheft, B., Stedman, K., Roberto, F., Willits, D., Gleske, A. K., Zoeller, L., et al. (2004). Comparative genomic analysis of hyperthermophilic archaeal
Fuselloviridae Viruses. J. Virol. 78, 1954-1961. doi: 10.1128/JVI.78.4.19541961.2004

Xu, Q., Teplow, D., Lee, T. D., and Abelson, J. (1990). Domain structure in yeast tRNA ligase. Biochemistry 29, 6132-6138. doi: 10.1021/bi00478a004

Xue, S., Calvin, K., and Li, H. (2006). RNA recognition and cleavage by a splicing endonuclease. Science 312, 906-991. doi: 10.1126/science.1126629

Yamasaki, S., Ivanov, P., Hu, G. F., and Anderson, P. (2009). Angiogenin cleaves tRNA and promotes stress-induced translational repression. J. Cell Biol. 185, 35-42. doi: 10.1083/jcb.200811106

Yoshida, H., Matsui, T., Yamamoto, A., Okada, T., and Mori, K. (2001). XBP1 mRNA is induced by ATF6 and spliced by IRE1 in response to ER stress to produce a highly active transcription factor. Cell 107, 881-891. doi: 10.1016/S00928674(01)00611-0

Yoshihisa, T., Ohshima, C., Yunoki-Esaki, K., and Endo, T. (2007). Cytoplasmic splicing of tRNA in Saccharomyces cerevisiae. Genes Cells 12, 285-297. doi: 10.1111/j.1365-2443.2007.01056.x

Yoshihisa, T., Yunoki-Esaki, K., Ohshima, C., Tanaka, N., and Endo, T. (2003). Possibility of cytoplasmic pre-tRNA splicing: the yeast tRNA splicing endonuclease mainly localizes on the mitochondria. Mol. Biol. Cell 14, 3266-3279. doi: 10.1091/mbc.E02-11-0757

Yoshinari, S., Shiba, T., Inaoka, D. K., Itoh, T., Kurisu, G., Harada, S., et al. (2009) Functional importance of crenarchaea-specific extra-loop revealed by an Xray structure of a heterotetrameric crenarchaeal splicing endonuclease. Nucleic Acids Res. 37, 4787-4798. doi: 10.1093/nar/gkp506

Zillmann, M., Gorovsky, M. A., and Phizicky, E. M. (1991). Conserved mechanism of tRNA splicing in eukaryotes. Mol. Cell. Biol. 11, 5410-5416.

Conflict of Interest Statement: The author declares that the research was conducted in the absence of any commercial or financial relationships that could be construed as a potential conflict of interest.

Received: 29 March 2014; accepted: 20 June 2014; published online: 10 July 2014. Citation: Yoshihisa T (2014) Handling tRNA introns, archaeal way and eukaryotic way. Front. Genet. 5:213. doi: 10.3389/fgene.2014.00213

This article was submitted to Non-Coding RNA, a section of the journal Frontiers in Genetics.

Copyright (C) 2014 Yoshihisa. This is an open-access article distributed under the terms of the Creative Commons Attribution License (CC BY). The use, distribution or reproduction in other forums is permitted, provided the original author(s) or licensor are credited and that the original publication in this journal is cited, in accordance with accepted academic practice. No use, distribution or reproduction is permitted which does not comply with these terms. 